\title{
Sistemática para avaliação e melhoria da flexibilidade de layout em ambientes dinâmicos
}

\author{
A method to measure and improve layout flexibility in \\ dynamic environments
}

\author{
Carla Simone Ruppenthal Neumann ${ }^{1}$ \\ Flávio Sanson Fogliatto ${ }^{2}$
}

\begin{abstract}
Resumo: Ambientes dinâmicos apresentam um alto grau de incerteza a respeito das necessidades futuras da produção. Tradicionalmente, para que um layout possa ser avaliado e melhorado, devem-se enfocar fatores de proximidade e de adjacência, já que os mesmos aumentam a eficiência da movimentação de materiais, reduzindo assim os custos operacionais. Adicionalmente, se sugere acrescentar robustez, flexibilidade, suficiência e utilização do espaço a esses fatores, o que reforça a idéia que parte da flexibilidade de layout $(F L)$ é devida à associação com outros tipos de flexibilidade de manufatura (FM). Neste artigo se propõe uma sistemática de avaliação e melhoria da FL em ambientes dinâmicos. Mais explicitamente, mensuram-se os habilitadores de um layout, que é capaz de reagir às incertezas externas e internas que surgem ao mudar as necessidades da produção. A sistemática é desenvolvida em nove etapas, as quais partem de matrizes que ponderam o impacto de fatores de proximidade de departamentos, de utilização de área produtiva e de associação com outros tipos de FM na avaliação da FL. Também se apresenta uma proposta de análise reversa do Desdobramento da Função Qualidade (QFD). As proposições apresentadas são ilustradas em um caso prático de uma empresa do setor metal-mecânico.
\end{abstract}

Palavras-chave: Flexibilidade de layout. Sistemática e ambientes dinâmicos.

\begin{abstract}
Dynamic environments are usually characterized by high uncertainty with respect to future production needs. In traditional layout evaluation, emphasis is placed on factors such as proximity and adjacency since they increase material handling efficiency reducing operational costs. It is usually recommended to consider additional factors in the analysis, such as robustness, flexibility, sufficiency, and use of space. These factors reinforce the idea that layout flexibility is in part related to other types of manufacturing flexibility. In this article, a method to evaluate and improve layout flexibility in dynamic environments is proposed. More explicitly, it is proposed the measurement of the enablers of a layout that is capable of reacting to external and internal uncertainties that arise due to changes in the production needs. The proposed method is implemented in nine stages using matrices to measure the impact of proximity between departments, using production space and an association with other types of manufacturing flexibility for layout flexibility evaluation. The present study also presents a proposition in which the traditional Quality Function Deployment (QFD) analysis is performed in reverse. The method is illustrated in a case study carried out in a company in the metal component processing industry.
\end{abstract}

Keywords: Layout flexibility. Method and dynamic environments.

\section{Introdução}

O planejamento do layout objetiva buscar uma combinação ótima entre os elementos que configuram as instalações industriais, sendo motivado pela existência de diferentes fluxos de produção e a utilização diferenciada do espaço físico. Ao se planejar, portanto, a melhoria de layout, se deve procurar a disposição que melhor conjugue equipamentos, força de trabalho, áreas produtivas, áreas de movimentação, áreas de armazenamento, produtos, fases do processo ou serviço de forma a permitir o máximo rendimento dos fatores de produção (LAHMAR; BENJAAFAR, 2005; MENG; HERAGU; ZIJM, 2004).

Verifica-se um incremento no número de autores que enfocam ambientes com alta turbulência e volatilidade, mas cujos layouts absorvem mudanças e se adaptam com facilidade as alterações futuras da produção.

\footnotetext{
${ }^{1}$ Departamento de Ciências Administrativas, Escola de Administração, Universidade Federal do Rio Grande do Sul - UFRGS, Rua Washington Luiz, 855, CEP 90010-460, Porto Alegre, RS, Brasil, e-mail: csrneumann @ea.ufrgs.br

${ }^{2}$ Departamento de Engenharia de Produção e Transportes, Universidade Federal do Rio Grande do Sul - UFRGS,

Av. Osvaldo Aranha, 99, 5o andar, CEP 90035-190, Porto Alegre, RS, Brasil, e-mail: ffogliatto@ producao.ufrgs.br
}

Recebido em 21/9/2009 — Aceito em 3/8/2012

Suporte financeiro: CNPq. 
Exemplos mais notórios incluem Rosenblatt e Lee (1987), Venkatadri, Rardin e Montreil (1997), Yang e Peters (1998), Askin et al. (1999), Kochar e Heragu (1999), Montreil, Venkatadri e Rardin (1999), Benjaafar e Sheikhzadeh (2000), Heragu e Zijm (2001), Benjaafar, Heragu e Irani (2002), Lahmar e Benjaafar (2005), Meng, Heragu e Zijm (2004), Elmaraghy (2006) e Irani e Huang (2006). Esses layouts, designados por dinâmicos, flexíveis ou reconfiguráveis, respondem rapidamente às incertezas e à variabilidade do mix de produtos, a variações no volume de produção, a variações na quantidade demandada e ao encurtamento do ciclo de vida dos produtos, enquanto continuam a minimizar a distância e maximizar a adjacência. Nesses ambientes, costuma-se afirmar que escopo tem mais importância que escala, correspondência tem mais importância do que custo e reconfigurabilidade tem mais importância do que eficiência (BENJAAFAR; HERAGU; IRANI, 2002).

Analisando o estado da arte sobre avaliação de diferentes configurações de layout, verificam-se oportunidades de melhoria. Majoritariamente a avaliação de um layout se baseia na solução de algoritmos computacionais, geralmente sujeitos a restrições que tendem a representar a realidade de forma simplista. Assim, as soluções apresentadas enfocam a redução dos custos de modo quase estático, pois minimizam as distâncias e maximizam a adjacência de departamentos que devem ficar próximos (FRANCIS; McGINNIS JUNIOR; WHITE, 1992). Entretanto, não se pode desprezar que o layout é parte integrante de um sistema de manufatura, que apresenta características dinâmicas e complexidade singular. Nesse contexto, é importante avaliar um projeto de layout por meio de um conjunto de indicadores, como de distância e adjacência, e acrescentar indicadores que meçam sua capacidade de operar também em ambientes dinâmicos, flexíveis e facilmente reconfiguráveis, como descritos por Benjaafar, Heragu e Irani (2002) e Raman, Nagalingam e Lin (2009).

Comparando-se as definições comumente empregadas para o termo layout e os diferentes tipos de flexibilidade de manufatura (FM), observa-se que a flexibilidade de layout (FL) poderia ser tomada como um tipo de FM que engloba um conjunto com diferentes combinações de tipos de FM tradicionalmente reconhecidos, o que muitas vezes torna difícil sua avaliação. Assim sendo, poder-se-ia determinar em que grau os diferentes tipos de FM impactam, em um layout mais adequado, uma situação dinâmica. Poucos autores que abordam a FM abordam a FL; dentre os quais, destacam-se Webster e Tyberghein (1980) e Yang e Peters (1998). Para eles, a FL é definida como a habilidade do layout reagir efetivamente às várias mudanças no ambiente fabril, causadas pelas transformações incessantes nas necessidades dos clientes e pelos distúrbios internos do negócio, em termos de custo e tempo. Na prática, a FL é representada pela variedade de pequenos rearranjos de layout que podem ser realizados com baixas penalizações em custos, para absorver as incertezas no ambiente fabril. Baixas penalizações em custos, por sua vez, significam minimização de perda de tempo e de esforços e maximização de desempenho ao efetuar mudanças. Relativamente a custos, consideram-se tanto o custo de movimentação das máquinas quanto o custo de produção perdida (horas paradas, redução de produtividade, etc). As incertezas podem ser decorrentes de acontecimentos, tais como: mudança de mix de produto; descontinuidade ou alteração de níveis de demanda; quebra de máquinas; absenteísmo elevado da força de trabalho; necessidade de alteração das características técnicas do sistema de movimentação; exigência de produtos com novas características físicas e técnicas; etc. Ao que parece, a FL gera um layout em que alguns pequenos rearranjos continuarão a ser rotineiros, porém serão efetivados com menores esforços. Outros rearranjos irão exigir esforços especiais, dependentes do tempo para execução, grau de planejamento e quantidade de recursos humanos, infraestruturais e econômicos envolvidos.

Neste artigo, apresenta-se uma sistemática que permite ponderar diferentes fatores para avaliar e melhorar a FL partindo do pressuposto de que a empresa está inserida em um ambiente dinâmico. Mensuram-se conjuntamente: $(i)$ indicadores relacionados aos diferentes tipos de FM consagrados na literatura; e (ii) fatores tradicionais de layout, como indicadores de proximidade de departamentos e utilização da área produtiva.

A sistemática para avaliação e melhoria da FL é composta de nove etapas, sendo que a proposição das etapas I, III e IV, apresentadas na Figura 1, exigiram extensa análise da literatura da área e são o ponto de partida para que o usuário determine sua FL. Na Etapa I se realiza o desdobramento dos fatores e dos indicadores que impactam a FL. Na Etapa III, elabora-se a árvore de FL, na qual o analista é solicitado a preencher os pesos de cada fator terciário de modo a refletir o impacto de cada fator de FL no ambiente específico a ser analisado. Na Etapa IV se elabora a matriz de FL; nela, os pesos atribuídos aos fatores terciários são relacionados com indicadores de FL. O grau de relação entre pares de itens é determinado a partir de extensa revisão bibliográfica, sendo esta uma importante contribuição deste trabalho. Como resultado do uso da matriz de FL, o analista obtém um peso de importância para cada indicador de FL. Em uma etapa posterior do método, a análise da matriz de FL é efetuada de modo reverso. Tal procedimento permite ao analista verificar o impacto do estado atual dos indicadores de FL medidos no ambiente analisado, sobre os fatores terciários de FL inicialmente valorados pela instalação na Etapa III. Na prática, essa análise permite verificar quais fatores 
terciários de FL são efetivamente oferecidos em nível satisfatório pela instalação analisada.

$\mathrm{O}$ artigo apresenta importantes contribuições na área de planejamento de layout de instalações industriais. A sistemática desenvolvida colabora para o avanço do tema, pois realiza um esforço de pesquisa bibliográfica, organiza hierarquicamente os fatores que impactam sobre a FL, além de propor a matriz de FL e o cálculo reverso. A sistemática permite mensurar a FL relativamente a aspectos tradicionais de avaliação, tais como proximidade de departamentos e utilização de área e sob aspectos dinâmicos, associados a tipos de FM, o que é contemplado ao desdobrarem-se fatores e indicadores, como exposto na Figura 1. A sistemática também gera um diagnóstico da situação atual, levando em conta o ambiente dinâmico presente no contexto de muitas empresas. Assim, preliminarmente à realização de mudanças físicas, pode-se realizar uma análise criteriosa das potencialidades e deficiências da instalação, priorizando as melhorias que colaboram para a FL e sinalizando a continuidade/descontinuidade de ações. A sistemática realiza a análise dos processos e capacidades reais internas, identifica deficiências e enumera oportunidades de melhoria, do ponto de vista restrito, aplicado a fluxos, máquinas e departamentos específicos. Também se podem avaliar indicadores de flexibilidade externos, como os ligados ao mercado e ao desenvolvimento de novos produtos, e ver como impactam na FL da instalação, do ponto de vista estratégico, aplicado à organização como um todo.
O restante deste artigo está organizado em quatro seções. Na seção 2, é apresentado um referencial teórico para a pesquisa aqui apresentada. A seção 3 é dedicada à apresentação da sistemática proposta, a qual é aplicada a um estudo de caso na seção 4 . O artigo é encerrado na seção 5, na qual são apresentadas as conclusões e desdobramentos futuros da pesquisa.

\section{Referencial teórico}

A sistemática desenvolvida aborda três temas: a FM, o layout de instalações e o layout em ambientes dinâmicos. Esses temas são entrelaçados, uma vez que o sistema de manufatura requer um projeto de layout de instalações adequado e frequentemente está inserido em um ambiente de mudanças constantes, também chamado de dinâmico. Neste artigo, o termo layout também tem a conotação de 'projeto de instalações', utilizando o sentido mais amplo de cunho estratégico. Não significa apenas definir se um determinado espaço será funcional, em linha, celular, misto e, em virtude da realidade atual, determinar entradas e saídas de materiais e posicionar máquinas e pessoas nesta área. As incertezas a que a manufatura está submetida devem ser consideradas para tornar o layout da instalação viável também nos períodos futuros.

Inicialmente deve-se determinar o que torna um layout flexível, capaz de reagir às incertezas que surgirem. Tradicionalmente enfocam-se critérios de proximidade e de adjacência entre os departamentos,
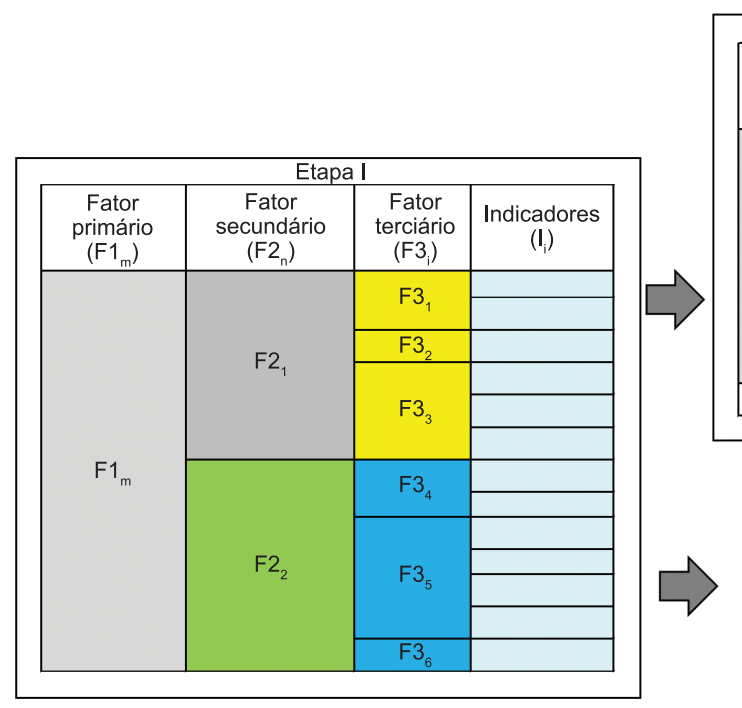

\begin{tabular}{|c|c|c|c|c|c|c|c|}
\hline \multicolumn{8}{|c|}{ Etapa III } \\
\hline $\begin{array}{c}\text { Fator } \\
\text { primário } \\
\left(\mathrm{F} 1_{\mathrm{m}}\right)\end{array}$ & $\begin{array}{c}\text { Fator } \\
\text { secundário } \\
\left(F 2_{n}\right)\end{array}$ & $\% F 2_{n}$ & $\begin{array}{c}\text { Fator } \\
\text { terciário } \\
\left(\mathrm{F}_{3}\right)\end{array}$ & Peso & $\% F 3_{i}$ & $\mathrm{IFF}_{\mathrm{i}}$ & $\mathrm{IFF}_{i}^{*}$ \\
\hline \multirow{8}{*}{$F 1_{m}$} & \multirow{3}{*}{$\mathrm{F} 2_{1}$} & & $\mathrm{~F} 3$ & Peso F3 & & & \\
\hline & & & $\mathrm{F}_{2}$ & Peso F3 & & & \\
\hline & & & $\mathrm{F}_{3}$ & Peso F 3 & & & \\
\hline & Peso F2 & $\% \mathrm{~F} 2$ & & & 100 & $\% \mathrm{~F} 2$ & \\
\hline & \multirow{3}{*}{$\mathrm{F}_{2}$} & & $\overline{F 3}$ & $\mathrm{Peso}_{\mathrm{F}}{ }_{4}$ & & & \\
\hline & & & $\mathrm{F} 3_{5}$ & Peso F $3_{5}$ & & & \\
\hline & & & $\mathrm{F} 3_{6}$ & Peso F3 & & & \\
\hline & Peso F2 ${ }_{2}$ & $\% \mathrm{~F}_{2}$ & & & 100 & $\% \mathrm{~F} 2_{2}$ & \\
\hline Total & & 100 & & & & 100 & \\
\hline
\end{tabular}

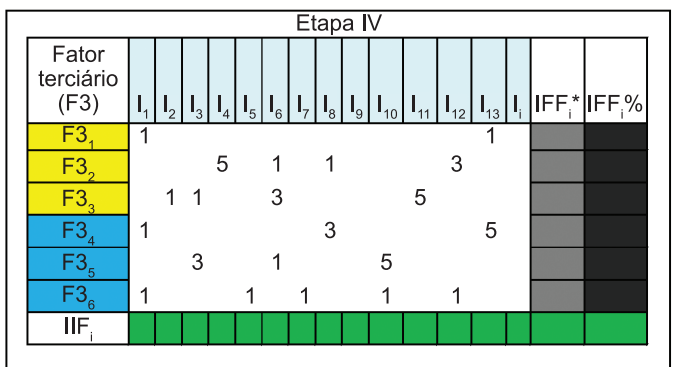

Figura 1. Sistemática de avaliação e melhoria de FL. 
os quais, nos níveis adequados, aumentam a eficiência da movimentação de materiais, reduzindo custos operacionais. Matematicamente, isso corresponde a uma função objetivo representada por equações de minimização de distâncias e maximização de adjacências (TOMPKINS et al.,1996; FRANCIS; McGINNIS JUNIOR; WHITE, 1992), o que será contemplado na sistemática proposta. Ao analisar a literatura sobre avaliação de layouts verifica-se que os principais critérios que apresentam dificuldades de mensuração são fluxo e ambiente. O critério de fluxo está subdividido em três classes: relacionado ao espaço, ao fluxo de materiais e à robustez e flexibilidade. O critério de ambiente está subdividido em duas classes: adjacência e qualidade do ambiente. Ao mesmo tempo que esses critérios confirmam as equações tradicionais, eles também antecipam a necessidade de ter robustez e flexibilidade, e de aperfeiçoar a utilização das áreas de máquinas, de armazenamento, de necessidades pessoais, de corredores e de movimentação pessoal, entre outras (LIN; SHARP, 1999a, b).

Para traçar um paralelo entre FM e FL, alguns conceitos básicos sobre FM fazem-se necessários. Sethi e Sethi (1990) definem a FM como a adaptabilidade da manufatura a diferentes circunstâncias, sujeita a incertezas externas e internas, sendo materializada pela capacidade da manufatura reconfigurar os recursos para produzir diferentes produtos de forma eficiente e com qualidade aceitável. Para Slack $(1983,1987)$, a FM é descrita pelos seguintes elementos: (i) amplitude dos estados que um sistema pode assumir; (ii) tempo necessário para se mover de um estado para outro; (iii) ruptura organizacional gerada; e (iv) custos para efetuar a mudança entre os estados. Tempo e custo são chamados "elementos de atrito", que restringem a resposta do sistema. A amplitude da flexibilidade diz respeito ao nível e ao tamanho da adaptação de um sistema, o que está relacionado com sua capacidade. Posteriormente, Koste e Malhotra $(1999,2000)$ e Koste, Malhotra e Sharma (2004) subdividiram o elemento amplitude em $(i)$ número de opções possíveis, e (ii) heterogeneidade, isto é, o grau de diferenciação entre recursos/opções do sistema. Exemplificando: uma máquina pode realizar um grande número de operações, mas todas do mesmo tipo, e assim ter uma grande amplitude de operações, mas uma baixa heterogeneidade. Por esse motivo, a construção dos fatores terciários, desdobrados na primeira etapa da sistemática proposta, privilegia estas subdivisões de elementos.

Diversas propostas de classificação dos tipos de FM encontram-se disponíveis na literatura. A classificação, como se conhece hoje, evoluiu ao longo dos anos e tem em Gerwin (1987, 1993), Browne et al. (1984), Sethi e Sethi (1990) e Suarez, Cusumano e Fine (1995) alguns de seus proponentes. Alguns exemplos de tipos de FM incluem máquinas, processo, força de trabalho, produto, materiais, volume, expansão e roteamento, entre outros; tais tipos formam um dos fatores primários de impacto sobre a FL, que será proposta na próxima seção. Sethi e Sethi (1990) propõem a existência de flexibilidades básicas em sistemas de manufatura. Koste e Malhotra (1999) agrupam os tipos de FM nos níveis de planta, de chão de fábrica e de recursos individuais, basicamente incorporando o componente das incertezas internas e externas.

Sob o enfoque da FL, foram analisados os trabalhos de Webster e Tyberghein (1980), Hassan (1994), Benjaafar e Ramakrishnan (1996), Yang e Peters (1998) e Meng, Heragu e Zijm (2004), entre outros. Esses trabalhos ajudam a explicitar a lógica de que parte da FL é devida a fatores primários de associação com outros tipos de FM. A intersecção desses trabalhos com a problemática da nova geração de layouts (MENG; HERAGU; ZIJM, 2004) resulta na proposição da associação entre os tipos de FM e o layout. De acordo com essa problemática, dado que existe um mix de produtos, determina-se o roteamento de acordo com as máquinas disponíveis e se propõe uma localização adequada, proveniente de um estudo de layout. A intersecção ocorre no momento em que as incertezas externas e internas forçam a alteração da localização de máquinas e elementos de apoio, ao mesmo tempo que desejam evitar rearranjos muito frequentes, tornando-se então um problema estratégico da organização. Essa intersecção é a base para propor a estrutura desdobrada na sistemática e encontrada na literatura da área.

Recentemente, trabalhos de Raman, Nagalingam e Chio (2005), Raman et al. (2007) e Raman, Nagalingam e Lin (2009) sintetizam essas ideias integrando o componente da FM para medir a efetividade de um layout, ao mesmo tempo que consideram a proximidade dos departamentos e a utilização da área produtiva. Os autores verificam o grau de proximidade de departamentos cuja adjacência é necessária, pois o objetivo é reduzir as distâncias para minimizar os custos de movimentação e os tempos de produção. Tais custos são derivados da análise do fluxo de materiais e não de materiais dentro e entre os departamentos de uma instalação. A utilização da área produtiva verifica a ocupação de maneira efetiva das áreas de máquinas, ferramentas, estocagem e transporte de materiais, bem como áreas inativas com atividades que adicionam valor ou não. Os tipos de FM que impactam diretamente no layout são a flexibilidade de expansão, de volume e de roteamento. A primeira tem relação direta com a existência e a facilidade de criar espaços livres; a segunda, com as variações de volume que o layout suporta; a terceira verifica a existência de operações/máquinas alternativas e acessíveis para produzir uma determinada peça/produto. Ao final, 
integram-se os tipos de FM por meio de uma média ponderada pelo peso de importância, obtendo-se um indicador de efetividade do layout.

Introduzidos esses três temas, a próxima seção apresenta e detalha a sistemática para avaliar e melhorar a FL.

\section{Apresentação da sistemática proposta}

Do ponto de vista da natureza, esta pesquisa é classificada como aplicada, visto que gera conhecimentos úteis à solução de problemas reais; do ponto de vista da forma de abordagem do problema, é classificada como qualitativa; do ponto de vista de seus objetivos, é classificada como explicativa, pois visa identificar os fatores que determinam ou contribuem para aumentar e flexibilidade de um layout, e aprofunda o conhecimento da realidade porque explica a razão dos fatos e o encadeamento dos fatores; do ponto de vista dos procedimentos técnicos é classificada como pesquisa experimental, pois se determina um objeto de estudo, selecionam-se as variáveis que seriam capazes de influenciá-lo e definem-se as formas de medição, de controle e de observação dos efeitos que a variável produz no objeto.

A sistemática para avaliação e melhoria da FL é constituída de nove etapas, apresentadas na Figura 2. Optou-se por utilizar o termo 'flexibilidade', pois ele é utilizado pelos autores da área de layout para enfocar layouts em ambientes dinâmicos, associados às características e requisitos atuais. Entretanto, poder-se-ia utilizar, sem prejuízo do sentido do termo, as expressões 'dinamicidade, reconfigurabilidade e robustez'. O termo flexibilidade foi adotado principalmente por não ser comum, na literatura de FM, encontrar o layout como tipo de FM. Entende-se que a $F L$ pode ser parcialmente atribuída à associação com os outros tipos de FM, os quais já podem estar sendo medidos e monitorados na instalação.

O modelo matemático utilizado neste artigo é parcialmente baseado em Fogliatto, Da Silveira e Royer (2003), que, por sua vez, se baseia na lógica do QFD. Os autores propõem um índice que estabelece a viabilidade da customização em massa de diferentes partes de um produto, levando em conta requisitos do cliente, flexibilidade de entrega dos fornecedores e flexibilidade da produção. Inicialmente se listam as características do produto a serem customizadas, explicitando seu peso de importância para o cliente. Esses itens, por sua vez, são correlacionados a partes de produtos, que são posteriormente correlacionadas aos estágios da manufatura. Ao final, se obtém um índice que ajuda a definir prioridades gerenciais e oportunidades de melhoria em termos de customização em massa das partes do produto. As principais adaptações feitas no modelo de Fogliatto, Da Silveira e Royer (2003) dizem respeito à aplicação da ferramenta e ao modelo matemático utilizado, uma vez que esse trabalho utiliza um menor número de matrizes e estabelece formas diferenciadas de preenchimento.

Na exposição que se segue, os índices $m, n, i$ e $j$ estão associados a fatores primários, secundários, terciários e indicadores, respectivamente. Adicionalmente, matrizes são identificadas por letras maiúsculas em negrito; matrizes transpostas são identificadas por $\mathrm{T}$ em sobrescrito; a inversa de uma matriz é identificada por -1 em sobrescrito; e vetores são identificados por

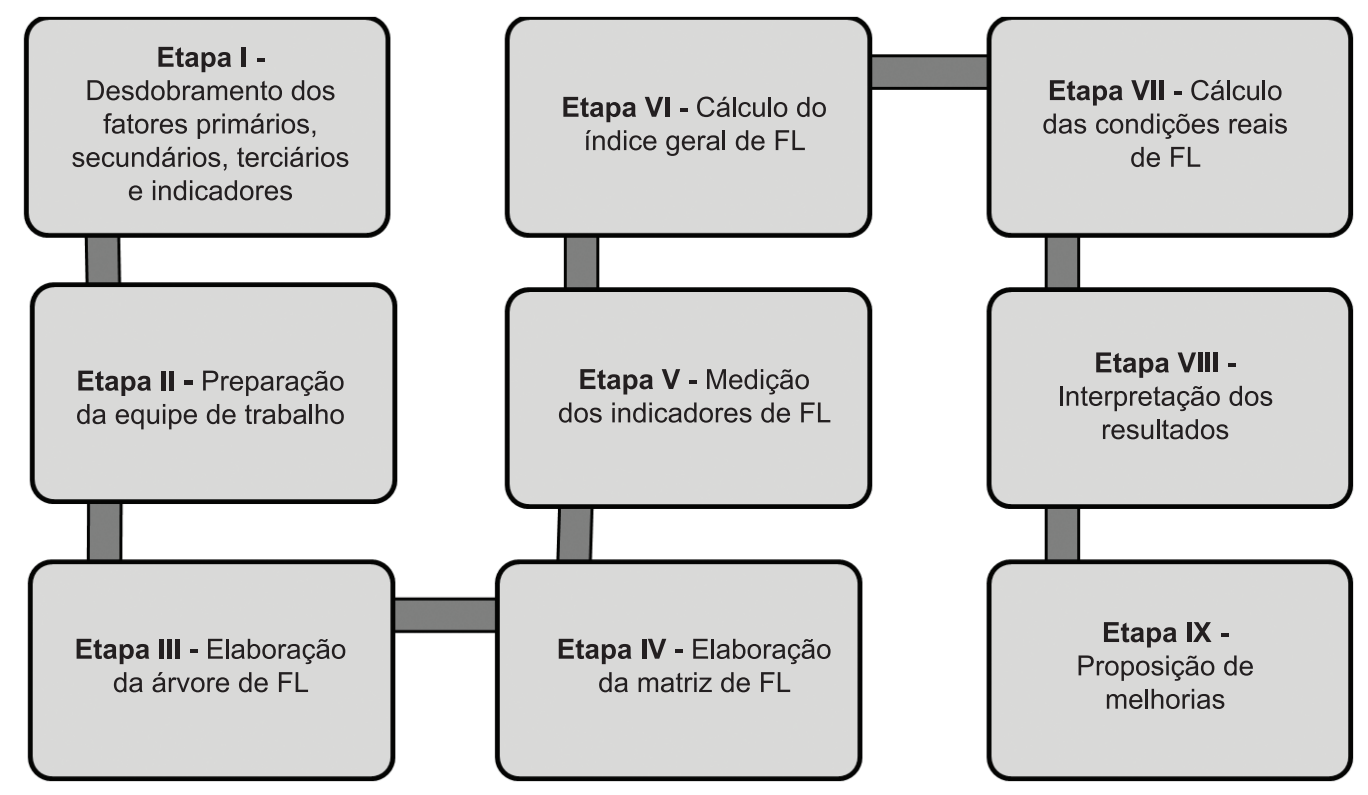

Figura 2. Etapas da sistemática de avaliação e melhoria de FL. 
letras minúsculas em negrito. O detalhamento das etapas é apresentado na sequência.

Na Etapa I, desdobram-se os fatores que têm influência sobre a FL, os quais são classificados em primários, secundários e terciários, conforme estrutura proposta na Tabela 1. Fatores terciários são vinculados a um conjunto de indicadores em uma matriz de relações ponderadas, esquematizada na etapa IV da Figura 1 e detalhados mais adiante. Ao todo são propostos 3 fatores primários, 12 fatores secundários, 33 fatores terciários e 50 indicadores. A lista de fatores na Tabela 1 não pode ser alterada pelo usuário da sistemática; admite-se apenas alterar o peso de importância de cada fator secundário e terciário na composição do valor total, o que é realizado na Etapa III. Na Tabela 1, a estrutura proposta para os fatores primários é a mesma de Raman, Nagalingam e Lin (2009); a estrutura de fatores secundários e terciários, entretanto, é proposição original deste trabalho e foi elaborada tal que: $(i)$ todos os fatores e indicadores possam ser medidos de forma quantitativa e pela mesma ferramenta de avaliação (representada

Tabela 1. Desdobramento de fatores primários, secundários e terciários.

\begin{tabular}{|c|c|c|c|}
\hline Fator primário $\left(\mathbf{F} 1_{\mathrm{m}}\right)$ & Fator secundário $\left(\mathbf{F} 2_{n}\right)$ & Fator terciário $(\mathbf{F 3})$ & Número \\
\hline \multirow{5}{*}{$\begin{array}{l}\text { Proximidade dos } \\
\text { departamentos }\end{array}$} & \multirow{3}{*}{ Fluxo de materiais } & Adequação de fluxo de materiais intra & 1 \\
\hline & & Adequação de fluxo de materiais inter & 2 \\
\hline & & Adequação do sistema de movimentação & 3 \\
\hline & \multirow{2}{*}{ Fluxo de não materiais } & Adequação do fluxo de pessoas & 4 \\
\hline & & Adequação do fluxo de informações (papéis) & 5 \\
\hline \multirow{5}{*}{$\begin{array}{l}\text { Utilização da área } \\
\text { produtiva }\end{array}$} & \multirow{2}{*}{$\begin{array}{l}\text { Área diretamente } \\
\text { envolvida no processo }\end{array}$} & Utilização da área de máquinas & 6 \\
\hline & & Utilização da área de armazenamento & 7 \\
\hline & \multirow{3}{*}{$\begin{array}{l}\text { Área que não está } \\
\text { diretamente envolvida no } \\
\text { processo }\end{array}$} & Utilização da área de espera e movimentação & 8 \\
\hline & & Utilização da área de transporte & 9 \\
\hline & & $\begin{array}{l}\text { Existência de restrições de área (colunas, } \\
\text { elevadores, paredes, escadas, circulação) }\end{array}$ & 10 \\
\hline \multirow{23}{*}{$\begin{array}{l}\text { Associação com } \\
\text { outros tipos de } \\
\text { flexibilidade de } \\
\text { manufatura }\end{array}$} & \multirow{3}{*}{ Expansão } & Existência de áreas desperdiçadas (mal usadas) & 11 \\
\hline & & Existência de área reservada para expansão & 12 \\
\hline & & Existência de configurações modulares & 13 \\
\hline & \multirow{3}{*}{ Volume } & Amplitude de variação de capacidade & 14 \\
\hline & & Adaptabilidade do sistema produtivo & 15 \\
\hline & & Acuracidade da previsão de demanda & 16 \\
\hline & \multirow{3}{*}{ Mix } & Amplitude do mix de produtos & 17 \\
\hline & & Heterogeneidade do mix de produtos & 18 \\
\hline & & Desempenho do mix de produtos & 19 \\
\hline & \multirow{3}{*}{ Mercado e novos produtos } & Amplitude de lançamento de novos produtos & 20 \\
\hline & & Heterogeneidade de lançamento de novos produtos & 21 \\
\hline & & $\begin{array}{l}\text { Demandas dos clientes (rapidez, confiabilidade e } \\
\text { custos) }\end{array}$ & 22 \\
\hline & \multirow{3}{*}{ Roteamento e operações } & Amplitude de rotas alternativas & 23 \\
\hline & & Heterogeneidade de rotas alternativas & 24 \\
\hline & & $\begin{array}{l}\text { Quantidade de erros de qualidade causados pelas } \\
\text { operações }\end{array}$ & 25 \\
\hline & \multirow[b]{2}{*}{ Força de trabalho } & Amplitude de tarefas que um operador pode efetuar & 26 \\
\hline & & $\begin{array}{l}\text { Heterogeneidade das tarefas que um operador pode } \\
\text { efetuar }\end{array}$ & 27 \\
\hline & \multirow{3}{*}{ Máquinas (produção) } & Amplitude das máquinas & 28 \\
\hline & & Heterogeneidade das máquinas & 29 \\
\hline & & Desempenho das máquinas & 30 \\
\hline & \multirow{3}{*}{ Sistema de movimentação } & Amplitude de caminhos do sistema de movimentação & 31 \\
\hline & & $\begin{array}{l}\text { Heterogeneidade do que é movimentado pelo } \\
\text { sistema de movimentação }\end{array}$ & 32 \\
\hline & & Desempenho do sistema de movimentação & 33 \\
\hline
\end{tabular}


por uma matriz única de correlações); (ii) todos os indicadores possam ser avaliados em relação a um alvo; e (iii) os tipos de flexibilidade associados ao layout possam ser ampliados agregando aqueles relacionados ao ambiente externo, tais como as flexibilidades de mix e de mercado. Salienta-se também que os indicadores oferecem medições para um ou mais fatores terciários, representados por sua intensidade de relacionamento. Os indicadores são apresentados ao longo da aplicação da sistemática.

Na Etapa II, prepara-se a equipe envolvida na sistemática de avaliação e melhoria de FL. Sugere-se realizar um levantamento preliminar na própria empresa, buscando entender as questões de mercado no qual ela está inserida, seu diferencial quanto aos principais concorrentes e sua lógica de produção para auxiliar na compreensão dos fatores terciários que afetam a FL. Também podem ser realizados levantamentos dos processos relacionados aos principais produtos, explicitando lógicas de fluxo, de compartilhamento de recursos e de restrições físicas.

Na Etapa III, é elaborada a árvore de FL, cuja estrutura genérica pode ser observada na Figura 1. Os pesos atribuídos devem diferenciar fatores que colaboram para tornar o layout atual flexível, gerando a $F L$. Salienta-se que, neste momento, o interesse de pesquisa é a avaliação do conjunto de fatores reais, não ideais ou almejados. A árvore é uma estrutura que pondera os fatores em três níveis, utilizando uma equipe de especialistas da instalação (ver exemplo na Tabela 2). Aos fatores primários, proximidade dos departamentos, utilização da área produtiva e associação com os outros tipos de flexibilidade de manufatura posicionados na primeira coluna da Tabela 1, são atribuídos pesos de 40, 25 e 35, respectivamente, por sugestão de Raman, Nagalingam e Lin (2009a). Aos fatores secundários e terciários, são atribuídos, pela equipe de especialistas da empresa, pesos de importância entre 0 e 10 . Tais pesos podem provir da opinião individual, da opinião coletiva coletada pela sistematização de grupos focados, da opinião obtida com o uso do método Delphi ou outra técnica considerada adequada. Em qualquer momento que uma instalação desejar verificar sua FL, essa atribuição de pesos deve ser refeita e modificada. No caso de formação de equipe para apropriação de pesos, recomenda-se uma equipe multifuncional.

Uma vez atribuídos pesos de importância aos fatores na árvore da FL, deve-se calcular índices de flexibilidade direto e corrigido para cada fator terciário. Para tanto, os seguintes passos são implementados: (i) calcular o percentual de importância dos fatores secundários e terciários; (ii) calcular o índice de flexibilidade do fator; e (iii) calcular o índice corrigido de flexibilidade do fator. $O$ percentual associado aos fatores secundários $\left(\% F 2_{n}\right)$ e terciários $\left(\% F 3_{i}\right)$ expressa a importância do fator em um dado nível relativamente aos demais fatores no mesmo nível.

$\mathrm{O}$ índice de flexibilidade do fator $\left(I F F_{i}\right)$ informa a sua importância do ponto de vista do cliente, além de refletir metas em termos de FL ou a FL já disponível na instalação. Seu cálculo é efetuado pela Equação 1:

$$
I F F_{i}=\% F 2_{n} \times\left(\% F 3_{i} / 100\right)
$$

Por fim, o índice corrigido de flexibilidade do fator $\left(I F F_{i}^{*}\right)$ ajusta os pesos no nível terciário para evitar situações nas quais o peso máximo do nível terciário, dentro do subgrupo, seja maior que o peso do subgrupo no nível secundário. Para tanto, utiliza-se a Equação 2, em que $I F F_{\max / s u b}$ é o valor máximo entre os $I F F_{i}$ do subgrupo.

$$
I F F_{i}^{*}=P_{F 2, n} \times\left(I F F_{i} / I F F_{\max / s u b}\right)
$$

Depois do cálculo desses índices, é possível analisar o impacto dos fatores secundários e terciários sobre a FL da instalação. Tais análises servem para guiar as ações de melhorias.

Na Etapa IV, se elabora a matriz de FL, cuja estrutura genérica pode ser observada na Figura 1. Nessa matriz, os fatores terciários são apresentados nas linhas e os indicadores nas colunas. O principal objetivo dessa etapa é o cálculo do índice de importância dos indicadores de flexibilidade $\left(I I F_{j}\right)$; tais resultados serão utilizados para calcular o índice geral de FL, na Etapa VI. A matriz de FL é apresentada no Anexo 1, sendo que os fatores terciários estão numerados de 1 a 33, de acordo com a Tabela 1.

Para o cálculo do $I I F_{j}$, seguem-se os seguintes passos: (i) estabelecer a intensidade de relacionamento existente entre os fatores terciários e os indicadores $\left(I R_{i j}\right)$; (ii) transformar o índice corrigido de flexibilidade do fator $\left(I F F_{i}^{*}\right)$ calculado na etapa III em valor percentual $\left(I F F_{i}^{*} \%\right)$; e (iii) calcular a importância do indicador de flexibilidade $\left(I I F_{j}\right)$.

A intensidade de relacionamento entre fatores terciários e indicadores é assinalada no cruzamento de linhas e colunas, no corpo da matriz da Figura 1, utilizando uma escala de 0 (relacionamento inexistente) a 5 (relacionamento forte). As intensidades de relacionamento foram estabelecidas por análise de literatura especializada, tendo sido consolidada pelos autores deste trabalho. Por tratar-se de uma das principais contribuições da sistemática aqui proposta, a alteração das intensidades é desaconselhada, a menos que se disponha de sólidas justificativas teóricas e empíricas para tanto.

O segundo passo é a transformação do $I F F_{i}^{*}$ em valor percentual $\left(I F F_{i}^{*} \%\right)$, realizada para eliminar efeitos de escala entre subgrupos do nível terciário. Desta forma, torna-se possível uma comparação direta de importância entre diferentes fatores terciários. 


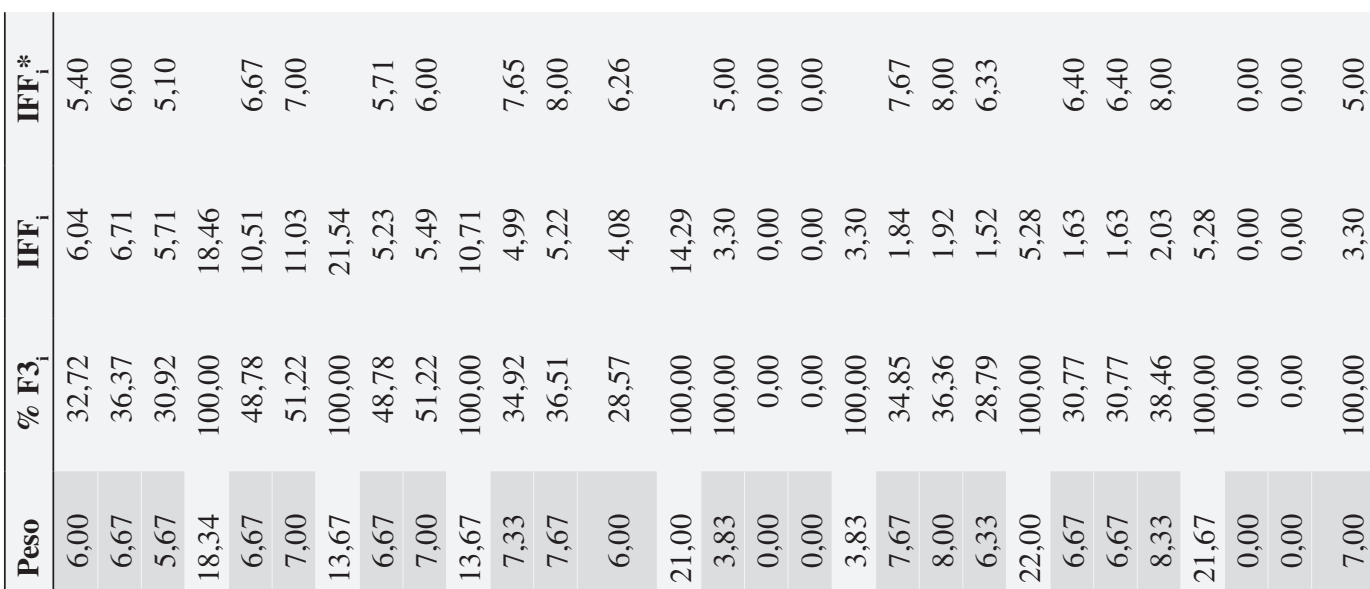

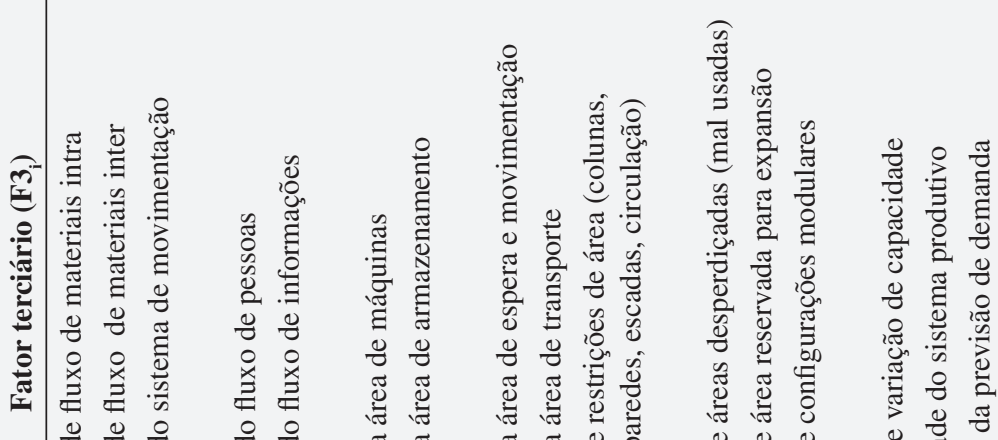

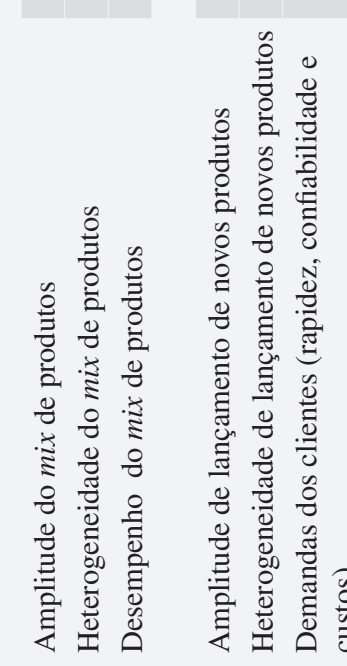

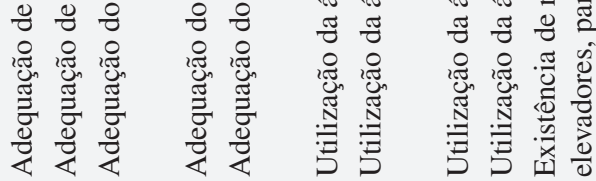

\&

.

$>$ ¿

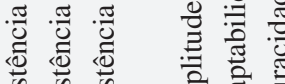

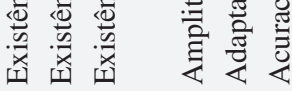

ते ले

m. in

$\begin{array}{ll}\infty & \infty \\ \text { in } & \text { nn }\end{array}$
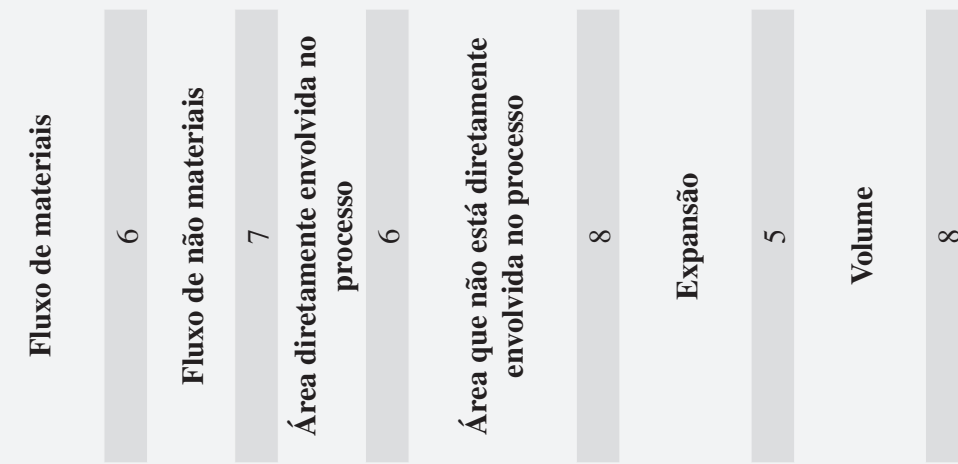

产
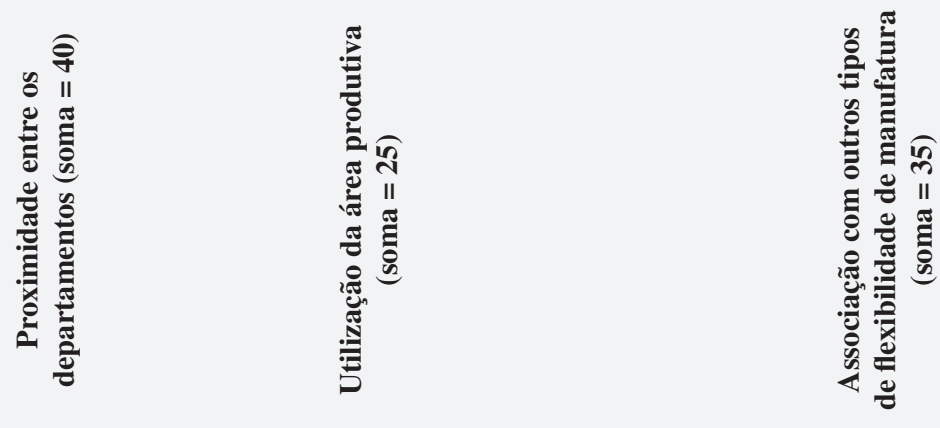


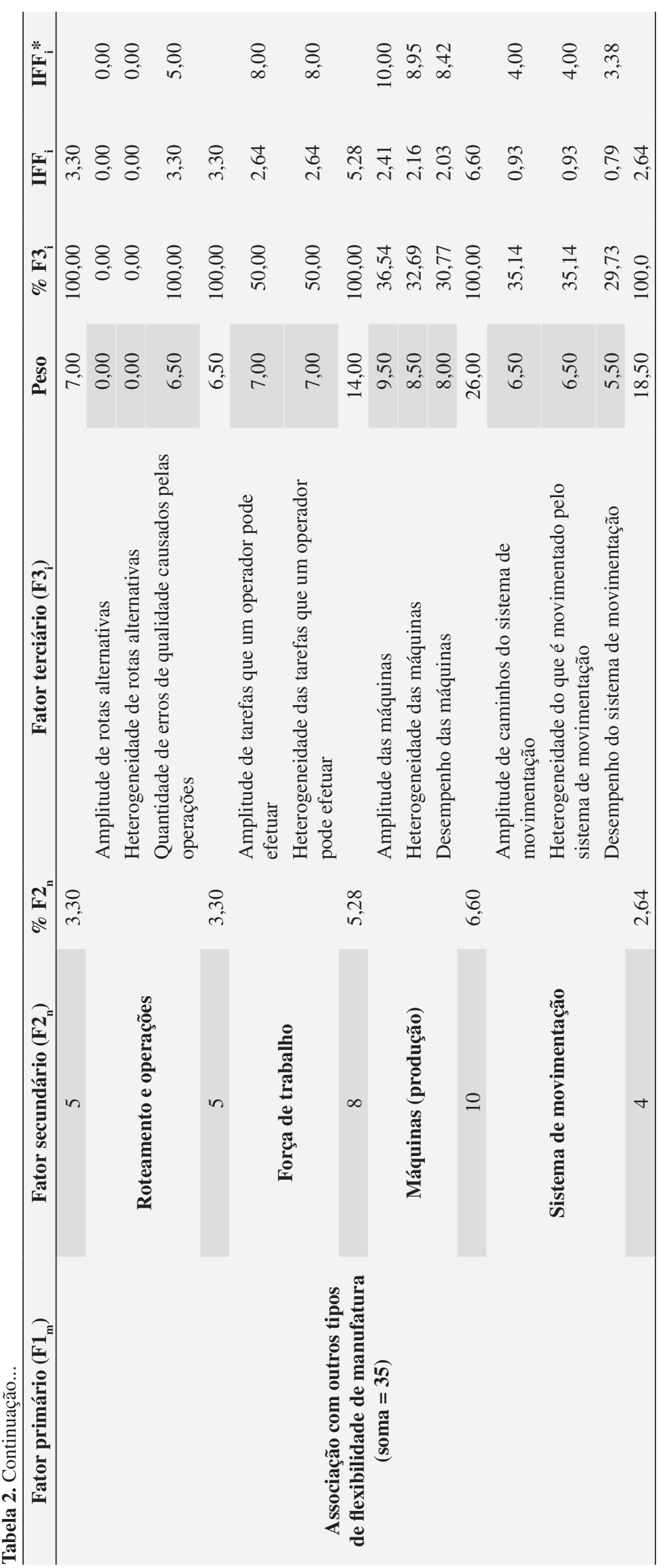


A importância do indicador de flexibilidade $\left(I I F_{j}\right)$ é dada pela soma de produtos entre o índice corrigido de flexibilidade dos fatores terciários e as intensidades de relacionamento dos indicadores. Para tanto, utiliza-se a Equação 3:

$$
I I F_{j}=\sum_{i=1}^{n} I F F_{i}^{*} \% \times I R_{i j}
$$

Na Etapa V, é feita a medição dos indicadores de FL no ambiente analisado. Para tanto, para cada indicador, é necessário: (i) estabelecer o valor-alvo; (ii) determinar a forma de medição; e (iii) medir localmente o valor atual do indicador. Indicadores podem apresentar diferentes valores-alvo; nessa proposta, entretanto, todos os indicadores são tratados como variáveis do tipo maior é melhor, com valor-alvo unitário.

Indicadores podem ser medidos utilizando três escalas: grau, proporção e razão. Aos indicadores do tipo grau, são atribuídas notas pela equipe da empresa; aos indicadores do tipo proporção, são aplicados cálculos proporcionais em relação ao total; aos indicadores do tipo razão, são aplicados cálculos proporcionais do ideal em relação ao real. São exemplos de indicadores o grau de facilidade de lançar novos produtos; o grau de frequência de rearranjo das máquinas; a proporção de máquinas duplicadas; a proporção de operadores multifuncionais; a razão da distância ideal/real para produzir produto típico; a razão de tempo de setup ideal/real; entre outros.

A medição de cada indicador é realizada localmente no ambiente analisado. Algumas leituras são de natureza quantitativa (ex: distância percorrida, tempo de setup, número de cruzamentos entre fluxos), enquanto outras envolvem avaliações subjetivas (ex: grau de inovação dos novos produtos, grau de variedade do mix). Todos os valores observados para os indicadores são convertidos em uma escala de 0 a 1 , em que 1 é o valor-alvo.

Na Etapa VI, calcula-se o índice geral de FL (IGFL), utilizando a Equação 4, em que $\boldsymbol{I}_{j / \text { med }}$ é a medição individual de cada indicador, efetuada na etapa V. O IGFL reflete a FL existente na instalação e pode ser utilizado de diversas formas. Se verificado periodicamente, sinaliza a evolução temporal da FL no ambiente analisado. $\mathrm{O}$ índice também pode ser utilizado em estudos em que se simula o impacto de diferentes pesos de importância para os fatores terciários sobre a FL.

$$
I G F L=\left(\sum_{j=1}^{n} I I F_{j} \times I_{j / \text { med }}\right) /\left(\sum_{j=1}^{n} I I F_{j}\right)
$$

Na Etapa VII, se aplica o cálculo reverso do QFD (FOGLIATTO; DA SILVEIRA; ROYER, 2003) sobre a matriz de FL. O objetivo é verificar como o nível atual dos indicadores, mensurados no ambiente de aplicação da sistemática e utilizados para corrigir os valores de $I I F_{j}$, impacta os fatores terciários de FL, ponderados em importância pelos analistas da empresa na Etapa III. Para um dado fator terciário $j$, três conclusões podem decorrer dessa verificação. $\mathrm{O}$ valor de $I F F_{i}$, após o cálculo reverso: $(i)$ mantém-se inalterado, indicando que a importância atribuída ao fator encontra sustentação empírica na empresa; (ii) aumenta, indicando folga nos fatores; ou (iii) diminui, indicando incapacidade da empresa em atender às demandas relativas à FL e apontando oportunidades para melhoria.

No cálculo do QFD reverso, proposto por Fogliatto, Da Silveira e Royer (2003), para se obter o vetor de flexibilidade do fator corrigido de forma a representar as condições reais dos fatores terciários, dados os níveis medidos dos indicadores, utiliza-se a Equação 5, em que $\mathbf{R}$ é a matriz de intensidade de relacionamentos, f é o vetor contendo os índices corrigidos de flexibilidade dos fatores terciários e i é o vetor de índices de importância do indicador de FL.

$$
f=\left(R \times R^{T}\right)^{-1} \times R \times i
$$

$\mathrm{Na}$ Etapa VIII, se interpretam os resultados. Por meio da priorização dos índices que compõem o índice geral, observam-se quais indicadores e fatores têm maior impacto na FL da instalação e quais, por possuírem pequeno impacto, podem ser negligenciados. Sugere-se elaborar gráficos elucidativos interpretando os resultados e comparando diferentes indicadores e fatores. Também se pode simular cenários com diferentes pesos para os fatores na árvore de FL (representando diferentes ações gerenciais, diferentes investimentos de recursos, diferentes reações do mercado, dos clientes e dos concorrentes) e discutir os resultados possíveis de ocorrer na prática.

Na Etapa IX, partindo de uma lista de estado atual dos indicadores e seu peso junto à matriz de FL, busca-se consenso sobre quais indicadores serão melhorados e quais já estão num nível aceitável, gerando um cronograma de implantação. Sugere-se gerar uma lista de priorizações e elaborar planos para as principais melhorias efetivadas. Alguns indicadores podem apontar para a necessidade de ações no nível supra, ou seja, de mudança física para um novo local. Neste caso, a sistemática informa uma série de requisitos que o novo local deve apresentar, auxilia no entendimento das questões necessárias para a melhoria dos fluxos, para a melhoria da utilização de áreas e para melhorar associações com outros tipos de FM. Estes requisitos devem ser explicitados para serem avaliados nos futuros layouts candidatos.

A reaplicação esporádica da sistemática pode auxiliar a entender o processo de adequação do 
layout como uma questão estratégica, mais ampla do que apenas designar novos locais para máquinas, departamentos e utilidades. Pelo fato de a aplicação da sistemática pressupor trabalho em grupo multidisciplinar, espera-se disseminar a cultura de estabelecer uma forma de avaliação e de proposição de pequenas mudanças, rotineiramente planejadas, que propiciem a obtenção de uma FL adequada às necessidades e às incertezas a que a instalação está submetida.

\section{Estudo de caso}

Essa seção ilustra a aplicação da sistemática proposta na seção 3 em uma empresa metal-mecânica. Como a FL não é um conceito de entendimento geral e inequívoco, esta ilustração tem o objetivo de exemplificar a aplicação da sistemática em um caso real, auxiliando no entendimento do que é avaliado ao medir a FL. A empresa atua no mercado de equipamentos e processos para a indústria de bebidas e possui 320 funcionários. Devido à experiência e detenção de tecnologia, realiza desde a concepção (projeto básico) até o comissionamento dos itens produzidos, passando pela seleção de equipamentos, execução e montagem final no cliente. Trabalha com projetos inteiramente customizados e corpo técnico totalmente especializado, fabricando produtos que se adaptam à necessidade de cada cliente; isto gera peculiaridades também na organização do layout fabril cuja FL seria desejável. Cabe enfatizar que o ambiente no qual a empresa está inserido é dinâmico, com incertezas externas relacionadas ao volume de produção e mix de produtos produzidos e comercializados.

O impacto das incertezas internas de produção é diminuído ao enfocar diferentes divisões de produtos, cada uma com suas peculiaridades de sistemas de movimentação, layout e organização do processo/ operação. A divisão dos produtos, em linhas gerais, resulta em quatro famílias, geradas pela distinção de processos de montagem final: carretas, lavadoras, pasteurizadores e tanques. Cada família possui características distintas de fabricação de peças; porém, até a chegada à montagem de produtos, as peças passam pelos mesmos departamentos. A empresa apresenta layout funcional, com foco nos processos, possuindo diversos departamentos especializados, tais como preparação, serralheria, pintura e polimento. A montagem final de cada família de produto ocorre em áreas separadas e independentes das outras. Todos os produtos percorrem longas distâncias até serem produzidos e têm cruzamentos de fluxo muito intensos.

A Etapa I da sistemática foi desenvolvida externamente à empresa. Desenvolveu-se uma lista externa de fatores de modo a contemplar todos os aspectos relativos à FL requerida pela empresa, conforme ilustrado na Tabela 2. A preparação da equipe de trabalho e a proposição das melhorias não serão descritas, por serem de interesse específico da empresa. Parte-se, então, para a apresentação das etapas III a VIII.

Na Etapa III foi elaborada a árvore de FL apresentada na Tabela 2. A elaboração ocorreu em uma reunião da qual participaram responsáveis por mudança de layout, pela produção, por projetos e por planejamento e controle da produção. Depois de algumas questões introdutórias e de contextualização ao ambiente em que a empresa está inserida, partiu-se para o preenchimento da árvore de FL. O peso dos fatores secundários foi obtido por consenso e por comparação entre diferentes fatores secundários, pertencentes a cada fator primário. $\mathrm{O}$ peso dos fatores terciários foi obtido por atribuição de nota em formulário individual, sem discussão entre os participantes. Todos os fatores foram explicados aos participantes e as dúvidas foram sanadas antes de se atribuir os pesos.

As células hachuradas na Tabela 2 foram preenchidas a partir da opinião dos participantes, utilizando uma escala de 0 a 10 . Na terceira, sexta, sétima e oitava colunas, são calculados, respectivamente, o peso de cada fator secundário, $o$ peso de cada fator terciário, o índice de flexibilidade do fator (Equação (1)) e o índice de flexibilidade do fator corrigido (Equação (2)). Observou-se que os maiores impactos ocorrem pelo fluxo de não materiais, fluxo de materiais, área não diretamente envolvida no processo, e assim por diante, conforme pode ser observado na terceira coluna da Tabela 2 . Os fatores terciários mais importantes para prover FL são amplitude das máquinas, heterogeneidade das máquinas, amplitude de tarefas que um operador pode efetuar, heterogeneidade das tarefas que um operador pode efetuar, e assim por diante, conforme pode ser observado na oitava coluna da Tabela 2.

Na Etapa IV, é elaborada e preenchida a matriz de FL. Inicialmente, determinam-se as intensidades de relacionamento $\left(I R_{i j}\right)$ no corpo da matriz e, de posse desses valores, calcula-se a importância de cada indicador, utilizando a Equação 3. É importante ressaltar que os valores de $I R_{i j}$ foram determinados pelos autores deste trabalho, a partir de análise da literatura.

Na Etapa V, os indicadores de FL foram avaliados na instalação para determinação de seu desempenho atual. Três exemplos, abordando diferentes tipos de indicadores, são aqui apresentados: $(i)$ ao grau de variação do peso do sistema de movimentação, foi atribuído o valor de 0,99 , justificado pelo fato de que estão atualmente à disposição pontes de diferentes capacidades, empilhadeiras, paleteiras e até um guindaste para movimentação de grandes pesos; (ii) à proporção de departamentos com adjacência correta foi atribuído o valor de 0,67 , correspondendo à razão 
entre 103 combinações de adjacência correta e o total de 153 adjacências analisadas; e (iii) à razão do custo ideal/real de setup, foi atribuído o valor de 0,90, calculado pela razão entre o custo ideal setup de um produto típico, que foi de $\mathrm{R} \$ 639,00$, e o custo real de setup de um produto típico, que foi de $\mathrm{R} \$ 710,00$.

Na Etapa VI, calcula-se o IGFL aplicando a Equação 4. O resultado foi 0,573 (lembre-se de que o valor varia de 0 até 1 ), como pode ser observado na Tabela 3. O baixo valor de IGFL reflete as deficiências da instalação e a penaliza em termos de FL, pois muitos indicadores permanecem próximos ao limite inferior; por exemplo: a proporção de área disponível para expansão futura; a proporção de máquinas com operações otimizadas; o grau de facilidade em aumentar a capacidade produtiva; o grau de frequência de rearranjo; o grau de facilidade em lançar novos produtos; o grau de inovação dos novos produtos; a proporção de quantidade de novos produtos lançados; a proporção de departamentos formados por tecnologia de grupo; e a razão entre tempo ideal e tempo real para lançamento de novos produtos.

Caso fosse simulado um aumento na proporção de pedidos atendidos; alteração da localização de departamentos-chave (como os almoxarifados de matérias-primas, por exemplo); alteração das matrizes de distância e adjacência; aumento da frequência de rearranjo; otimização dos tempos de setup e dos tempos de processamento; e treinamento da força de trabalho para melhorar a qualidade dos produtos; entre outras ações viáveis, o IGFL poderia ser melhorado. Entretanto, observa-se que o atingimento do IGFL máximo requer um esforço considerável da instalação, compatível com um prazo longo, principalmente no que se refere à criação da cultura de melhorias no que diz respeito à FL.

Na Etapa VII, para determinar a FL da instalação, refletida pela mensuração do status dos indicadores, utilizou-se o QFD reverso [Equação (5)]. Os resultados dessas operações podem ser observados na Tabela 4 .

A segunda coluna apresenta os $I F F_{i}^{*} \%$ calculados que são os mesmos da Tabela 2, porém convertidos para uma escala de 0 a 1 para facilitar a comparação entre si. Observa-se que todos os valores são positivos. A terceira coluna apresenta o peso do fator terciário, utilizando o cálculo reverso do QFD. Observam-se tanto valores positivos quanto negativos.

Na quarta coluna, é possível observar se, após o cálculo reverso do QFD, ocorre aumento (A), diminuição (D) ou inalteração (I) do fator terciário, justificado pelas diferenças de intensidades de relacionamento na matriz. São exemplos de fatores terciários, que apresentam folga de desempenho nos indicadores a ele relacionados, a amplitude de caminhos do sistema de movimentação, a heterogeneidade de rotas alternativas, a adequação do sistema de movimentação e a existência de áreas desperdiçadas. São exemplos de fatores terciários, que apresentam incapacidade em atender às demandas realtivas à FL, a adequação do fluxo de materiais inter e intra, o desempenho das máquinas e a amplitude das máquinas. Dois dos fatores terciários, a amplitude de variação de capacidade e a amplitude do mix de produtos, encontram sustentação empírica, sem folga, na empresa.

A quinta e a sexta colunas apresentam a priorização do fator terciário na FL, levando em conta a matriz original de FL e o cálculo reverso do QFD, respectivamente. Verifica-se que os especialistas da instalação atribuem um peso de importância diferenciado e geram um ordenamento diferente dos fatores terciários, e comparação ao ordenamento resultante do cálculo reverso do QFD. Por exemplo, a amplitude das máquinas, de acordo com a árvore de FL, é um dos fatores terciários que mais contribui ( $1^{\text {a }}$ colocada) para aumentar a FL. Entretanto, ao medir os indicadores, se observa que a proporção de máquinas com setup e operações otimizadas, multitarefas ou duplicadas é muito baixa; as máquinas estão mal distribuídas e, por isso, percorrem-se grandes distâncias; os operadores não são multifuncionais, o que leva a amplitude das máquinas a contribuir negativamente para a FL e ocupar o posicionamento de $25^{\text {a }}$ colocada no ranking.

Outro exemplo é o desempenho do sistema de movimentação que, pelos resultados da árvore de FL, ocupa a penúltima colocação. Ao medir os indicadores, se observa que o desempenho do sistema de movimentação melhora (passa a ser o $15^{\circ}$ colocado), fato que é explicado pela grande variação de volume e peso admitida pela instalação; pela variedade de caminhos; pelos altos tempos inoperantes das máquinas; pela alta quantidade de máquinas interligadas pelo sistema de movimentação; e pela grande quantidade de contenedores multiuso, o que melhora o valor deste indicador. É provável que tais diferenças também sejam influenciadas pela inserção dos especialistas em um contexto externo e interno específico, bem como pelas suas expectativas pessoais e de grupo.

Nas Etapas VIII e IX, se interpretam os resultados e se propõem melhorias que aumentem a FL. A árvore de FL elaborada, baseada na opinião dos especialistas da empresa, permite observar a ordem de importância dos fatores de terciários que colaboram para dar FL, sob a ótica dos envolvidos no processo. Os resultados desta ponderação vêm apresentados na Tabela 2 e na Tabela 4. Observa-se que para os especialistas: (i) todos os pesos dos fatores terciários são positivos (por definição, eles não podem ser negativos); (ii) não ocorre diferenciação entre amplitude e heterogeneidade; (iii) existe supervalorização de 
Tabela 3. Cálculo de IGFL.

\begin{tabular}{|c|c|c|c|}
\hline Indicadores $\left(\mathbf{I}_{\mathbf{j}}\right)$ & $I I F_{j}(\mathbf{1})$ & $I_{j / m e d}(2)$ & $(1) \times(2)$ \\
\hline Grau de adequação do sistema de produção ao volume de produção & 1,76 & 0,80 & 1,41 \\
\hline Proporção do mix que é produzido na planta & 1,39 & 0,99 & 1,38 \\
\hline Proporção de área servida pelo sistema de movimentação & 1,36 & 0,95 & 1,29 \\
\hline Proporção de máquinas interligadas pelo sistema de movimentação & 1,27 & 0,95 & 1,21 \\
\hline Proporção de pedidos atendidos & 1,28 & 0,80 & 1,03 \\
\hline Grau de variedade do mix & 1,09 & 0,90 & 0,98 \\
\hline Proporção de contenedores multiuso & 1,02 & 0,95 & 0,97 \\
\hline Razão do número de cruzamentos de fluxos ideal/real & 1,65 & 0,53 & 0,88 \\
\hline Razão do custo ideal/real de processamento & 0,95 & 0,90 & 0,86 \\
\hline Proporção de departamentos com adjacência correta & 1,26 & 0,67 & 0,84 \\
\hline Proporção de área produtiva & 1,18 & 0,70 & 0,82 \\
\hline Proporção de área sem restrições & 0,80 & 1,00 & 0,80 \\
\hline Proporção da produção para atender a pedidos programados & 0,89 & 0,90 & 0,80 \\
\hline Razão de tempo de processamento ideal/real & 0,79 & 0,97 & 0,76 \\
\hline Proporção de área de armazenamento & 0,76 & 0,96 & 0,73 \\
\hline Razão do custo ideal/real de setup & 0,79 & 0,90 & 0,71 \\
\hline Grau de qualidade dos produtos & 0,69 & 0,92 & 0,63 \\
\hline Grau de facilidade de adequar o mix & 1,05 & 0,60 & 0,63 \\
\hline Razão de tempo de setup ideal/real & 0,66 & 0,95 & 0,63 \\
\hline Proporção de produtos com mercado consolidado & 0,56 & 0,90 & 0,51 \\
\hline Proporção da produção Just in time & 0,61 & 0,80 & 0,49 \\
\hline Proporção de departamentos com forma geométrica adequada & 0,60 & 0,78 & 0,46 \\
\hline Proporção de departamentos com área adequada & 0,55 & 0,83 & 0,46 \\
\hline Proporção de operações que máquina típica pode executar & 0,87 & 0,50 & 0,43 \\
\hline Grau de variação de volume do sistema de movimentação & 0,43 & 0,99 & 0,43 \\
\hline Grau de variação de peso do sistema de movimentação & 0,42 & 0,99 & 0,42 \\
\hline Grau de similaridade entre os novos produtos e os antigos & 0,50 & 0,80 & 0,40 \\
\hline Proporção de tempo inoperante das máquinas & 1,01 & 0,39 & 0,39 \\
\hline Razão da distância ideal/real para produzir produto típico & 1,62 & 0,23 & 0,38 \\
\hline Proporção de operações que operador sabe executar & 0,50 & 0,61 & 0,31 \\
\hline Proporção de operadores multifuncionais & 0,65 & 0,45 & 0,29 \\
\hline Proporção de departamentos que podem aumentar capacidade produtiva & 0,40 & 0,56 & 0,22 \\
\hline Proporção de máquinas com setup otimizado & 0,80 & 0,27 & 0,22 \\
\hline Proporção de tempo que o sistema de movimentação não é utilizado & 0,84 & 0,25 & 0,21 \\
\hline Proporção de máquinas duplicadas & 0,58 & 0,31 & 0,18 \\
\hline Proporção de máquinas multifuncionais & 0,83 & 0,19 & 0,16 \\
\hline Proporção de partes com rotas alternativas de processamento & 1,00 & 0,15 & 0,15 \\
\hline Proporção de máquinas de pequeno porte & 0,48 & 0,31 & 0,15 \\
\hline Proporção de área servida por corredores & 0,77 & 0,19 & 0,15 \\
\hline Proporção de processos mapeados & 0,72 & 0,17 & 0,12 \\
\hline Grau de facilidade de estabelecer rotas alternativas & 0,33 & 0,10 & 0,03 \\
\hline Proporção de máquinas com operações otimizadas & 0,84 & 0,04 & 0,03 \\
\hline Proporção de área disponível para expansão futura & 0,42 & 0,07 & 0,03 \\
\hline Grau de frequência de rearranjo & 1,71 & 0,01 & 0,02 \\
\hline Grau de facilidade de aumentar capacidade produtiva & 0,43 & 0,03 & 0,01 \\
\hline Grau de facilidade de lançar novos produtos & 0,34 & 0,01 & 0,00 \\
\hline Grau de inovação dos novos produtos & 0,18 & 0,01 & 0,00 \\
\hline Proporção de quantidade de novos produtos lançados & 0,17 & 0,01 & 0,00 \\
\hline Proporção de departamentos formados por tecnologia de grupo & 0,92 & 0,00 & 0,00 \\
\hline Razão de tempo para lançamento ideal/real de novos produtos & 1,20 & 0,00 & 0,00 \\
\hline$I G F L$ & & 0,573 & \\
\hline
\end{tabular}


Tabela 4. Comparação entre os fatores terciários, utilizando a matriz de FL e cálculo reverso do QFD.

\begin{tabular}{|c|c|c|c|c|c|}
\hline \multirow{2}{*}{ Fator terciário $\left(\mathbf{F 3}_{\mathrm{i}}\right)$} & \multirow{2}{*}{$\begin{array}{l}\text { Matriz } \\
\text { FL (1) }\end{array}$} & \multirow{2}{*}{$\begin{array}{l}\text { Cálculo } \\
\text { reverso (2) }\end{array}$} & \multirow{2}{*}{$\mathbf{I}, \mathbf{A}, \mathbf{D}$} & \multicolumn{2}{|c|}{ Priorização } \\
\hline & & & & (1) & (2) \\
\hline Amplitude de caminhos do sistema de movimentação & 0,023 & 0,195 & A & 14 & 1 \\
\hline Heterogeneidade do mix de produtos & 0,036 & 0,147 & A & 8 & 2 \\
\hline Adequação do sistema de movimentação & 0,029 & 0,102 & A & 12 & 3 \\
\hline Heterogeneidade de rotas alternativas & 0,000 & 0,099 & A & 16 & 4 \\
\hline Existência de áreas desperdiçadas (mal-usadas) & 0,028 & 0,092 & A & 13 & 5 \\
\hline Amplitude de tarefas que um operador pode efetuar & 0,045 & 0,088 & A & 4 & 6 \\
\hline Acuracidade da previsão de demanda & 0,036 & 0,077 & A & 8 & 7 \\
\hline Quantidade de erros de qualidade causados pelas operações & 0,028 & 0,071 & A & 13 & 8 \\
\hline Utilização da área de máquinas & 0,032 & 0,071 & A & 10 & 9 \\
\hline Adequação do fluxo de informações (papéis) & 0,040 & 0,062 & A & 6 & 10 \\
\hline Heterogeneidade das máquinas & 0,051 & 0,056 & A & 2 & 11 \\
\hline Demandas dos clientes (rapidez, confiabilidade e custos) & 0,028 & 0,039 & A & 13 & 13 \\
\hline Desempenho do sistema de movimentação & 0,019 & 0,030 & A & 15 & 15 \\
\hline Amplitude do mix de produtos & 0,036 & 0,038 & $\mathrm{~A}, \mathrm{I}$ & 8 & 14 \\
\hline Amplitude de variação de capacidade & 0,043 & 0,043 & I & 5 & 12 \\
\hline Heterogeneidade das tarefas que um operador pode efetuar & 0,045 & 0,025 & $\mathrm{D}$ & 4 & 16 \\
\hline Adequação de fluxo de materiais intra & 0,031 & 0,009 & $\mathrm{D}$ & 11 & 17 \\
\hline Adaptabilidade do sistema produtivo & 0,045 & 0,008 & $\mathrm{D}$ & 4 & 18 \\
\hline Utilização da área de transporte & 0,045 & 0,002 & $\mathrm{D}$ & 4 & 19 \\
\hline Existência de área reservada para expansão & 0,000 & $-0,003$ & $\mathrm{D}$ & 16 & 20 \\
\hline Utilização da área de espera e movimentação & 0,043 & $-0,010$ & $\mathrm{D}$ & 5 & 21 \\
\hline Amplitude de lançamento de novos produtos & 0,000 & $-0,012$ & $\mathrm{D}$ & 16 & 22 \\
\hline Utilização da área de armazenamento & 0,034 & $-0,019$ & $\mathrm{D}$ & 9 & 23 \\
\hline Existência de configurações modulares & 0,000 & $-0,032$ & $\mathrm{D}$ & 16 & 24 \\
\hline Amplitude das máquinas & 0,057 & $-0,036$ & $\mathrm{D}$ & 1 & 25 \\
\hline Heterogeneidade de lançamento de novos produtos & 0,000 & $-0,038$ & $\mathrm{D}$ & 16 & 26 \\
\hline Adequação do fluxo de pessoas & 0,038 & $-0,051$ & $\mathrm{D}$ & 7 & 27 \\
\hline $\begin{array}{l}\text { Existência de restrições de área (colunas, elevadores, } \\
\text { paredes, escadas, circulação) }\end{array}$ & 0,036 & $-0,057$ & $\mathrm{D}$ & 8 & 28 \\
\hline Adequação de fluxo de materiais inter & 0,034 & $-0,062$ & $\mathrm{D}$ & 9 & 29 \\
\hline Desempenho das máquinas & 0,048 & $-0,075$ & $\mathrm{D}$ & 3 & 30 \\
\hline Desempenho do mix de produtos & 0,045 & $-0,081$ & $\mathrm{D}$ & 4 & 31 \\
\hline $\begin{array}{l}\text { Heterogeneidade do que é movimentado pelo sistema de } \\
\text { movimentação }\end{array}$ & 0,023 & $-0,099$ & $\mathrm{D}$ & 14 & 32 \\
\hline Amplitude de rotas alternativas & 0,000 & $-0,158$ & $\mathrm{D}$ & 16 & 33 \\
\hline
\end{tabular}

máquinas e número de operadores; e (iv) se tolera o desperdício de recursos (excesso).

A matriz de FL elaborada permite observar o peso de importância de cada indicador que colabora para a FL, sob a ótica dos diferentes graus de força de relacionamento internos, ao mesmo tempo que leva em conta a opinião dos especialistas da empresa.

$\mathrm{O}$ índice geral de FL permite posicionar a empresa relativamente a outras empresas no que diz respeito à FL, simular melhorias nos indicadores, simular alteração de pesos nos fatores secundários e terciários e verificar o impacto nesses índices, o que é apresentado na Tabela 3. O cálculo reverso do
QFD permite verificar o status dos fatores terciários frente ao nível de desempenho observado para os indicadores na empresa. Observa-se que, pelo cálculo reverso: (i) alguns fatores terciários são positivos e outros negativos; (ii) ocorre diferenciação entre amplitude e heterogeneidade; (iii) os fatores são fortemente afetados pelas diferentes intensidades de relacionamento que existem entre os indicadores; e (iv) as relações de melhoria dos indicadores nem sempre têm impacto explícito e direto nos fatores.

A reaplicação periódica da sistemática de avaliação da FL permite aos envolvidos entender o processo de adequação do layout como uma questão estratégica, 
mais ampla do que apenas designar novos locais para máquinas, departamentos e utilidades. Observa-se que a FL medida pela sistemática não privilegia apenas o fluxo de materiais inter e intra (que é diretamente afetado pela razão da distância, pela proporção de departamentos com adjacência correta, pela proporção de departamentos com forma e área adequada, por exemplo), mas também outros tipos de FM. Ao fazer isto, avalia-se o número e heterogeneidade de máquinas, operadores e sistemas que auxiliam a movimentação de materiais, questões relacionadas ao mercado e lançamento de novos produtos e questões de mix, entre outras. Cabe aos envolvidos no processo decidir quais melhorias devem ser implementadas e com quais ineficiências conviver-se-á.

\section{Conclusões}

Atributos desejáveis de layouts que absorvem mudanças com facilidade, característicos de instalações flexíveis, têm sido objeto frequente de pesquisa na área de produção. Este fato se deve à grande incerteza a que estão submetidas às instalações, tanto em requisitos externos (gerados pelo mercado, pelos clientes e fornecedores) quanto em requisitos internos (gerados por configurações das áreas, localização dos departamentos, máquinas, força de trabalho, sistema de movimentação).

Nesse contexto, a FL representa um ganho para empresas, principalmente no que se refere à sua mensuração, aqui representada por uma sistemática de avaliação e melhoria. A análise dos principais autores da literatura apontou para a existência de três lacunas no processo de mensuração da FL, que foram abordadas na sistemática proposta e que são contribuições deste trabalho: (a) ausência de um objeto de variação da FM que represente a FL; $(b)$ pequeno número de autores que pesquisam sobre quesitos de avaliação de layouts; e (c) dificuldade de reunir quesitos de proximidade, adjacência e de associação com outros tipos de FM para representar a FL.

A sistemática desenvolvida: ( $i$ ) desdobra os fatores primários, secundários e terciários que têm importância no aumento da FL; (ii) estabelece pesos de importância para cada fator; (iii) estabelece indicadores para medir a FL; (iv) estabelece a intensidade de relacionamento de cada indicador com o conjunto de fatores terciários; (v) prioriza os indicadores; (vi) mede localmente os níveis de cada indicador; (vii) calcula um índice geral de flexibilidade; (viii) avalia as potencialidades reais de $F L$; e (ix) verifica as principais oportunidades de melhoria do layout da instalação.

Do ponto de vista gerencial, a sistemática de avaliação e melhoria da FL auxiliou na identificação dos fatores primários, secundários, terciários e indicadores, cuja melhoria representa maiores ganhos em quesitos valorados pela instalação (representado pela opinião de seus especialistas), e impacto real dos indicadores na instalação. A análise utilizando os resultados da matriz de FL permite que as ações de melhorias iniciem pelos indicadores com maior peso nos índices FL. Por sua vez, a análise utilizando o cálculo reverso do QFD permite que os direcionamentos de melhoria sejam iniciados pelos fatores terciários mais deficitários em termos de FL. O desenvolvimento da sistemática e sua aplicação prática em uma instalação resultaram numa forma alternativa de mensurar a FL. Verificou-se a utilidade de agrupar os diferentes fatores sob a mesma ferramenta de avaliação e a facilidade de gerar as análises comparativas, por exemplo, utilizando planilhas eletrônicas. Sugere-se que os envolvidos reapliquem-na de tempos em tempos a fim de convergir para a obtenção de dados mais realistas de suas potencialidades e deficiências.

Entre os ganhos potenciais decorrentes do uso da sistemática proposta destacam-se: (a) estabelecimento de ações de melhorias contínuas nos indicadores; (b) redução de custos operacionais pela melhoria da utilização da área, melhoria da adjacência e redução das incertezas das necessidades futuras da produção; (c) redução de custos pela possibilidade de simulação da alteração nos pesos de fatores e seu impacto na FL em diferentes períodos; e (d) redução nos custos de movimentação das máquinas e no custo de produção perdida.

Como trabalho futuro, sugere-se aplicar a sistemática em outros contextos de aplicação, como o setor de serviços, e verificar as adaptações necessárias. Pretende-se também hierarquizar os tipos de FM que compõem o fator primário de 'associação com outros tipos de flexibilidade de manufatura', utilizando, por exemplo, a lógica de Koste e Malhotra (1999). Poder-se-á também desenvolver uma ferramenta matemática para avaliar a independência dos indicadores e dos fatores primários, de forma a evitar que dois ou mais indicadores meçam o mesmo aspecto de FL da instalação, o que potencialmente distorceria o cálculo do índice geral e do cálculo reverso do QFD.

\section{Referências}

ASKIN, R. G.; CIARALLO, F. W.; LUNDGREN, N. H. An empirical evaluation of holonic and fractal layouts. International Journal of Production Research, v. 37, n. 5, p. 961-978, 1999. http://dx.doi. org/10.1080/002075499191355

BENJAAFAR, S.; HERAGU, S. S.; IRANI, S. A. Next generation factory layouts: research challenges and recent progress. Interfaces, v. 32, n. 6, p. 58-76, 2002. http://dx.doi.org/10.1287/inte.32.6.58.6473

BENJAAFAR, S.; RAMAKRISHNAN, R. Modeling measurement and evaluation of sequencing flexibility in manufacturing systems. International Journal of Production Research, v. 34, n. 5, p. 1195-1220, 1996. http://dx.doi.org/10.1080/00207549608904961

BENJAAFAR, S.; SHEIKHZADEH, M. Design of flexible plant layouts. IIE Transactions, v. 32, n. 4, p. 309-322, 2000. http://dx.doi.org/10.1080/07408170008963909 
BROWNE, J. et al. Classification of flexible manufacturing systems. The FMS Magazine, v. 2, n. 2, p. 114-117, 1984.

ELMARAGHY, H. A. Flexible and reconfigurable manufacturing systems. International Journal of Flexible Manufacturing Systems, v. 17, n. 4, p. 261-276, 2006. http://dx.doi.org/10.1007/s10696-006-9028-7

FOGLIATTO, F. S.; DA SILVEIRA, G. J. C.; ROYER, R. Flexibility-driven index for measuring mass customization feasibility on industrialized products. International Journal of Production Research, v. 41, n. 8, p. 1811-1829, 2003. http://dx.doi. org/10.1080/1352816031000074991

FRANCIS, R. L.; McGINNIS JUNIOR, L. F.; WHITE, J. A. Facility Layout and Location: an analytical approach. Prentice Hall: Upper Saddle River, 1992.

GERWIN, D. An agenda for research on the flexibility of manufacturing processes. International Journal of Operations \& Production Management, v. 7, n. 1, p. 38-49, 1987. http://dx.doi.org/10.1108/eb054784

GERWIN, D. Manufacturing flexibility: a strategic perspective. Management Science, v. 39, n. 4, p. 395-410, 1993. http://dx.doi.org/10.1287/ mnsc. 39.4.395

HASSAN, M. M. D. Machine layout problem in modern manufacturing facilities. International Journal of Production Research, v. 32, n. 11, p. 2559-2584, 1994. http://dx.doi.org/10.1080/00207549408957084

HERAGU, S.; ZIJM, H. Design and performance evaluation of agile manufacturing systems. Enschede: Faculty of Mathematical Sciences, University of Twente, 2001. Working Paper.

IRANI, S. A.; HUANG, H. Cascading flow lines and layout modules: practical strategies for machine duplication in facility layouts. International Journal of Flexible Manufacturing Systems, v. 17, n. 2, p. 119-149, 2006. http://dx.doi.org/10.1007/s10696-006-8124-z

KOCHAR, J. S.; HERAGU, S. S. Facility layout design in a changing environment. International Journal of Production Research, v. 37, n. 11, p. 2429-2446, 1999. http://dx.doi.org/10.1080/002075499190590

KOSTE, L. L.; MALHOTRA, M. K. Trade-offs among the elements of flexibility: a comparison from the automotive industry. Omega, v. 28, n. 6, p. 693-710, 2000. http:// dx.doi.org/10.1016/S0305-0483(00)00027-X

KOSTE, L. L.; MALHOTRA, M. K.; SHARMA, S. Measuring dimensions of manufacturing flexibility. Journal of Operations Management, v. 22, n. 2, p. 171-196, 2004. http://dx.doi.org/10.1016/j. jom.2004.01.001

KOSTE, L. L.; MALHOTRA, M. K. A theoretical framework for analyzing the dimensions of manufacturing flexibility. Journal of Operations Management, v. 18 , n. 1, p. 75-93, 1999. http://dx.doi.org/10.1016/ S0272-6963(99)00010-8

LAHMAR, M.; BENJAAFAR, S. Design of distributed layouts. IIE Transactions, v. 37, n. 4, p. 303-318, 2005. http://dx.doi.org/10.1080/07408170590517015

LIN, L. C.; SHARP, G. P. Quantitative and qualitative indices for the plant layout evaluation problem. European Journal of Operational Research, v. 116, n. 1, p. 100-117, 1999a. http://dx.doi.org/10.1016/ S0377-2217(98)00046-0
LIN, L. C.; SHARP, G. P. Application of the integrated framework for the plant layout evaluation problem. European Journal of Operational Research, v. 116, n. 1, p. 118-138, 1999b. http://dx.doi.org/10.1016/ S0377-2217(98)00174-X

MENG, G.; HERAGU, S. S.; ZIJM, H. Reconfigurable layout problem. International Journal of Production Research, v. 42, n. 22, p. 4709-4729, 2004. http://dx.doi. org/10.1080/0020754042000264590

MONTREIL, B.; VENKATADRI, U.; RARDIN, R. L. Fractal layout organization for job shop environments. International Journal of Production Research, v. 37, n. 3, p. 501-521, 1999. http://dx.doi. org/10.1080/002075499191643

RAMAN, D.; NAGALINGAM, S. V.; CHIO, M. A fuzzy rule based system to measure facility layout flexibility. In: INTERNATIONAL CONFERENCE ON PRODUCTION RESEARCH, 18., 2005, Fisciano. Proceedings... University of Salerno, 2005.

RAMAN, D. et al. Effectiveness measurement of facilities layout. In: INTERNATIONAL MATADOR CONFERENCE, 35., 2007. Proceedings... Springer, 2007. p. 165-169.

RAMAN, D.; NAGALINGAM, S. V.; LIN, G. C. I. Towards measuring the effectiveness of a facilities layout. Robotics and Computer-Integrated Manufacturing, v. 25, n. 1, p. 191-203, 2009a. http://dx.doi.org/10.1016/j. $\operatorname{rcim} .2007 .06 .003$

ROSENBLATT, M. J.; LEE, H. L. A robustness approach to facilities design. International Journal of Production Research, v. 25, n. 4, p. 479-486, 1987. http://dx.doi. org/10.1080/00207548708919855

SETHI, A. K.; SETHI, S. P., Flexibility in manufacturing: a survey. The International Journal of Flexible Manufacturing Systems, v. 2, n. 4, p. 289-328, 1990. http://dx.doi.org/10.1007/BF00186471

SLACK, N. Flexibility as a manufacturing objective. International Journal of Operations \& Production Management, v. 3, n. 3, p. 4-13, 1983. http://dx.doi. org/10.1108/eb054696

SLACK, N. The flexibility of manufacturing systems. International Journal of Operations \& Production Management, v. 7, n. 4, p. 35-45, 1987. http://dx.doi. org/10.1108/eb054798

SUAREZ, F. F.; CUSUMANO, M. A.; FINE, C. H. An empirical study of flexibility in manufacturing. Sloan Management Review, v. 37, n. 1, p. 25-32, 1995.

TOMPKINS, J. A. et al. Facilities planning. New York: John Wiley \& Sons, Inc., 1996.

VENKATADRI, U.; RARDIN, R. L.; MONTREIL, B. A design methodology for fractal layout organization. IIE Transactions, v. 29, n. 10, p. 911-924, 1997. http:// dx.doi.org/10.1080/07408179708966411

WEBSTER, D. B.; TYBERGHEIN, M. B. Measuring flexibility of job-shop layouts. International Journal of Production Research, v. 18, n. 1, p. 21-29, 1980. http://dx.doi.org/10.1080/00207548008919646

YANG, T.; PETERS, B. A. Flexible machine layout design for dynamic and uncertain production environments. European Journal of Operational Research, v. 108, n. 1, p. 49-64, 1998. http://dx.doi.org/10.1016/ S0377-2217(97)00220-8 
Anexo 1. Matriz de FL ( Intensidade de relacionamento: 5 = forte; 3 = médio; $1=$ fraca; 0 = inexistente).

\begin{tabular}{|c|c|c|c|c|c|c|c|c|c|c|c|c|c|c|c|}
\hline 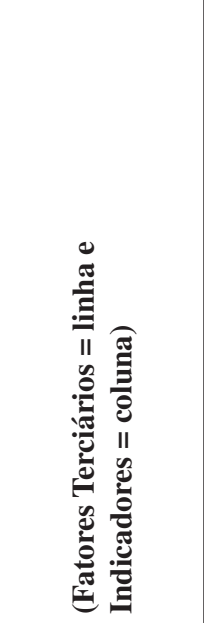 & 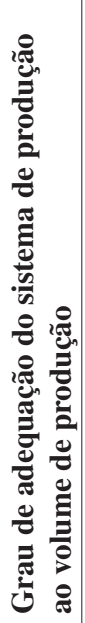 & 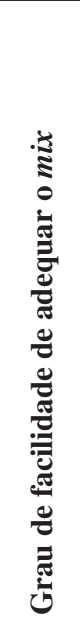 & 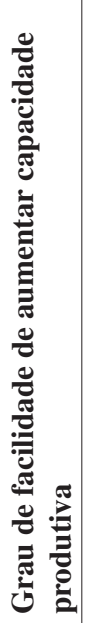 & 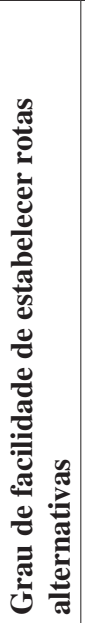 & 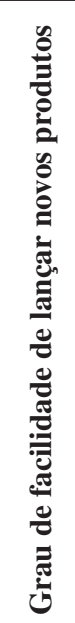 & 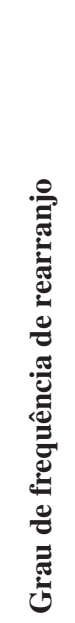 & 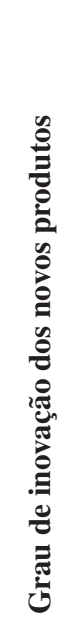 & 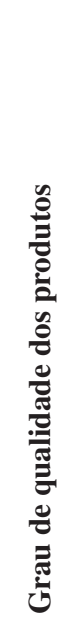 & 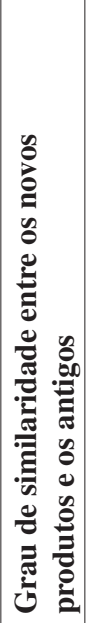 & 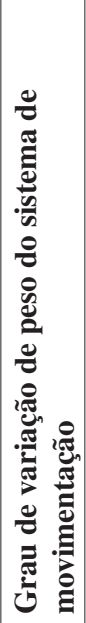 & 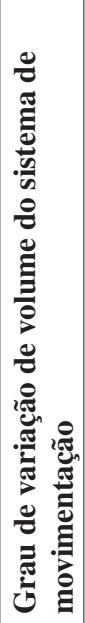 & 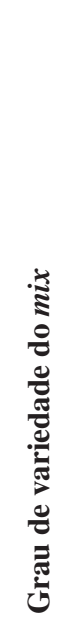 & 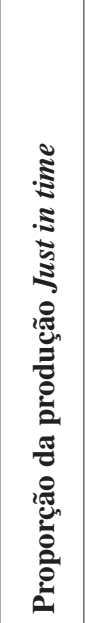 & 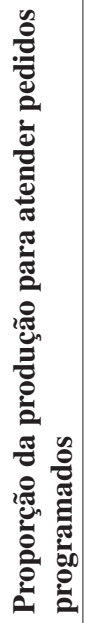 & 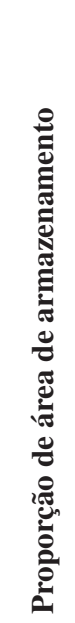 \\
\hline 1 & 1,0 & 1,0 & & 1,0 & & 3,0 & & 1,0 & 1,0 & 1,0 & & & & 1,0 & \\
\hline 2 & 5,0 & 1,0 & & 3,0 & & 5,0 & & & & 3,0 & 1,0 & & 1,0 & 1,0 & 1,0 \\
\hline 3 & 3,0 & 1,0 & & & & 1,0 & & 3,0 & & 3,0 & 3,0 & & 1,0 & 1,0 & \\
\hline 4 & 1,0 & 1,0 & & & & 1,0 & & & & & & & 1,0 & & \\
\hline 5 & 5,0 & 1,0 & & & & 1,0 & & & & & & & & & \\
\hline 6 & 5,0 & & 3,0 & & & 5,0 & & & & & 1,0 & & 3,0 & 3,0 & \\
\hline 7 & 3,0 & & 1,0 & & & 3,0 & & & & & 1,0 & & & 1,0 & 5,0 \\
\hline 8 & 3,0 & & 1,0 & & & 3,0 & & & & & & & 1,0 & 3,0 & \\
\hline 9 & 3,0 & & 1,0 & & & 3,0 & & & & & & & 1,0 & 3,0 & \\
\hline 10 & 1,0 & & 3,0 & & & & & & & & & & & & 3,0 \\
\hline 11 & & & & & & 3,0 & & & & & & & & 3,0 & 3,0 \\
\hline 12 & & & 3,0 & & & & & & & & & & & & 3,0 \\
\hline 13 & & & 5,0 & & & 1,0 & & & & & & 1,0 & & & \\
\hline 14 & 3,0 & & & & & & & & 1,0 & & & & & & \\
\hline 15 & & 3,0 & & & & 3,0 & & & & 1,0 & 1,0 & 3,0 & & & \\
\hline 16 & & & & & & & & & & & & 5,0 & 5,0 & 5,0 & 5,0 \\
\hline 17 & & 1,0 & & & 1,0 & & & & 3,0 & & & 3,0 & & & \\
\hline 18 & & 1,0 & & & 1,0 & & 3,0 & & & 1,0 & 1,0 & 5,0 & & & \\
\hline 19 & & 1,0 & & & 1,0 & & & & 3,0 & & & 3,0 & & & \\
\hline 20 & & 1,0 & & & 3,0 & & 5,0 & & 3,0 & & & 1,0 & & & \\
\hline 21 & & & & & 3,0 & & 3,0 & & & & & 3,0 & & & \\
\hline 22 & & 3,0 & & & 1,0 & 1,0 & 1,0 & 5,0 & & & & & 3,0 & 1,0 & 3,0 \\
\hline 23 & & 1,0 & & 1,0 & & 1,0 & & & & & & & 1,0 & 1,0 & \\
\hline 24 & 3,0 & & & 1,0 & & & & & & & & & & & \\
\hline 25 & & 3,0 & & 5,0 & & 1,0 & & 5,0 & 3,0 & & & & & & 3,0 \\
\hline 26 & & & & & 1,0 & & & & & & & & & 1,0 & \\
\hline 27 & & 3,0 & & & 1,0 & & & 1,0 & 1,0 & & & 3,0 & & & \\
\hline 28 & & 1,0 & 1,0 & 1,0 & 1,0 & 3,0 & & & & & & 1,0 & 1,0 & 1,0 & \\
\hline 29 & 3,0 & 3,0 & 1,0 & & 1,0 & 3,0 & & & 1,0 & & & 3,0 & & & \\
\hline 30 & 5,0 & 1,0 & & & & 3,0 & 1,0 & 5,0 & & & & & & & \\
\hline 31 & 3,0 & 1,0 & & & & 1,0 & & & & & & & & & \\
\hline 32 & 1,0 & 1,0 & & & & 1,0 & & & & 1,0 & 3,0 & & & & \\
\hline 33 & 3,0 & 1,0 & & & & 1,0 & & & & 5,0 & 5,0 & & & & 1,0 \\
\hline $\begin{array}{c}\text { Importância } \\
\text { do indicador } \\
\text { Flexibilização } \\
\text { Layout }\left(\mathrm{IIF}_{\mathrm{j}}\right)=\end{array}$ & 0,00 & 0,00 & 0,00 & 0,00 & 0,00 & 0,00 & 0,00 & 0,00 & 0,00 & 0,00 & 0,00 & 0,00 & 0,00 & 0,00 & 0,00 \\
\hline
\end{tabular}


Anexo 1. Continuação...

\begin{tabular}{|c|c|c|c|c|c|c|c|c|c|c|c|c|c|c|c|}
\hline 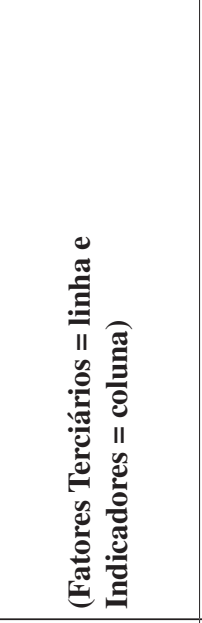 & 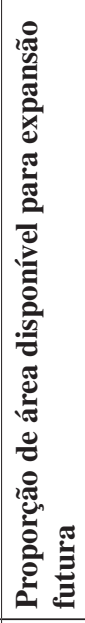 & 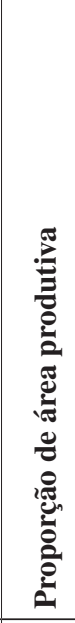 & 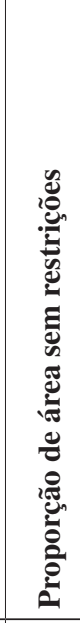 & 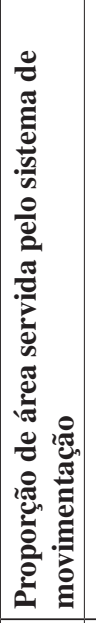 & 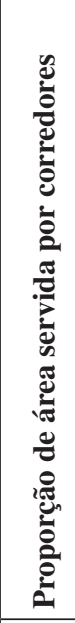 & 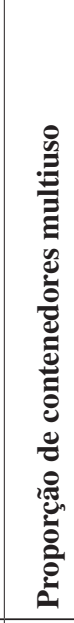 & 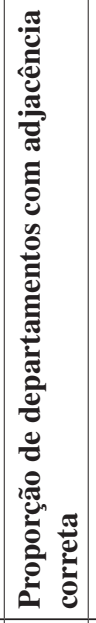 & 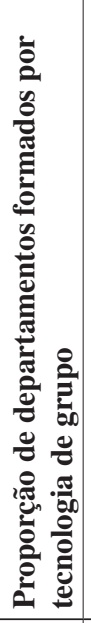 & 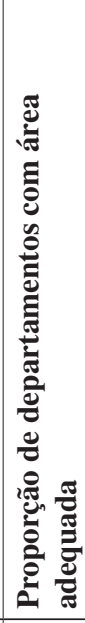 & 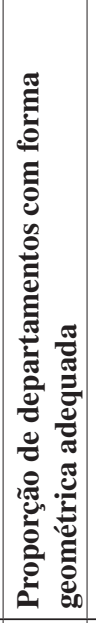 & 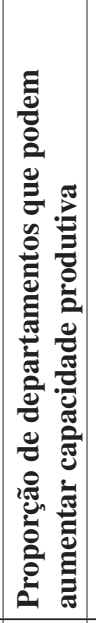 & 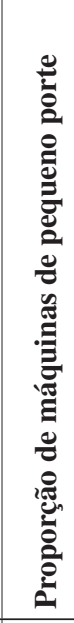 & 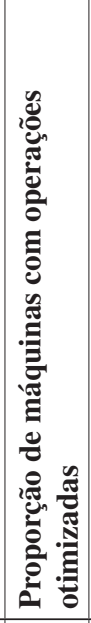 & 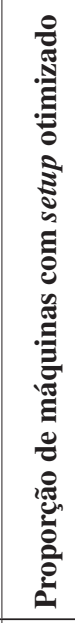 & 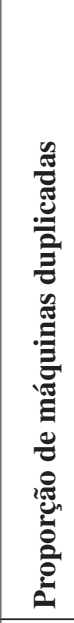 \\
\hline 1 & & 3,0 & 3,0 & 3,0 & & 1,0 & 3,0 & & 5,0 & 1,0 & 1,0 & 3,0 & 3,0 & 3,0 & 3,0 \\
\hline 2 & 3,0 & 3,0 & 3,0 & 5,0 & 3,0 & 3,0 & 5,0 & 3,0 & 1,0 & 5,0 & & & 3,0 & 3,0 & 3,0 \\
\hline 3 & & 1,0 & 3,0 & 5,0 & 5,0 & 3,0 & 3,0 & 1,0 & 3,0 & 1,0 & & & & & \\
\hline 4 & & 1,0 & & & & & & & & & & & & 1,0 & \\
\hline 5 & & 1,0 & & & & & & & & & & & & & \\
\hline 6 & & 5,0 & 3,0 & 3,0 & & & & 1,0 & 1,0 & 1,0 & 1,0 & 1,0 & 3,0 & 3,0 & 1,0 \\
\hline 7 & 1,0 & 3,0 & 1,0 & 1,0 & 3,0 & & & & & & 3,0 & & & & \\
\hline 8 & 1,0 & 1,0 & 1,0 & 1,0 & & 3,0 & & 1,0 & & & 1,0 & & & & \\
\hline 9 & 1,0 & 3,0 & 1,0 & 1,0 & 3,0 & 5,0 & & & 1,0 & 1,0 & 1,0 & & & & \\
\hline 10 & 1,0 & 3,0 & 5,0 & & 5,0 & & 3,0 & & 1,0 & 3,0 & & 1,0 & & & \\
\hline 11 & 1,0 & 3,0 & & & 1,0 & 1,0 & 3,0 & & 3,0 & 3,0 & 5,0 & & & 1,0 & \\
\hline 12 & 5,0 & 1,0 & & & & & 3,0 & & 3,0 & & 5,0 & 1,0 & & & 3,0 \\
\hline 13 & & & 1,0 & 3,0 & & & & & & & & 3,0 & & & 3,0 \\
\hline 14 & 3,0 & 1,0 & & 3,0 & & & & & & & & & 1,0 & 1,0 & \\
\hline 15 & & & & 1,0 & & 3,0 & 3,0 & & & & & & & 1,0 & \\
\hline \multicolumn{16}{|l|}{16} \\
\hline 17 & & 1,0 & & & & & & & & & & & & & \\
\hline 18 & & 1,0 & & & & & & & & & & 1,0 & & & 1,0 \\
\hline 19 & & & & & & 1,0 & & & & & & & & & \\
\hline 20 & & 1,0 & & & & & & & & & & & & & \\
\hline \multicolumn{16}{|l|}{21} \\
\hline 22 & & & & 1,0 & & & & & & & & & 1,0 & 1,0 & 3,0 \\
\hline 23 & & & & 3,0 & & & & & & & & & & & 1,0 \\
\hline 24 & & & & 3,0 & & 1,0 & & & & & & & & & \\
\hline 25 & & & & 1,0 & & & & & & & & & 5,0 & 1,0 & \\
\hline 26 & & 1,0 & & & & & & & & & & & & 1,0 & \\
\hline 27 & & & & & & & & 5,0 & & & & & & & \\
\hline 28 & & 1,0 & & 3,0 & & & 3,0 & 5,0 & 1,0 & 1,0 & & 1,0 & 3,0 & 1,0 & 1,0 \\
\hline 29 & & & & 1,0 & & & 5,0 & 3,0 & & & & 3,0 & & 1,0 & 3,0 \\
\hline 30 & & & & & & & 1,0 & 1,0 & & & & 1,0 & 3,0 & 3,0 & \\
\hline 31 & & 1,0 & 3,0 & 5,0 & 1,0 & 3,0 & 3,0 & & & 1,0 & & 1,0 & & & 1,0 \\
\hline 32 & & & & 3,0 & & 3,0 & 1,0 & & & & & & & & \\
\hline 33 & & & 3,0 & 5,0 & 3,0 & 5,0 & 1,0 & & 1,0 & 1,0 & & & 1,0 & & \\
\hline $\begin{array}{c}\text { Importância } \\
\text { do indicador } \\
\text { Flexibilização } \\
\text { Layout }\left(\mathrm{IIF}_{\mathrm{j}}\right)=\end{array}$ & 0,00 & 0,00 & 0,00 & 0,00 & 0,00 & 0,00 & 0,00 & 0,00 & 0,00 & 0,00 & 0,00 & 0,00 & 0,00 & 0,00 & 0,00 \\
\hline
\end{tabular}


Anexo 1. Continuação...

\begin{tabular}{|c|c|c|c|c|c|c|c|c|c|c|c|c|c|c|c|}
\hline 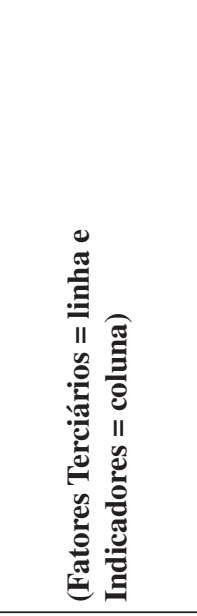 & 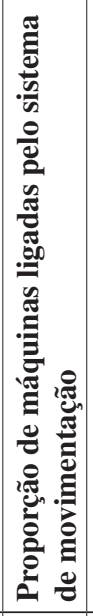 & 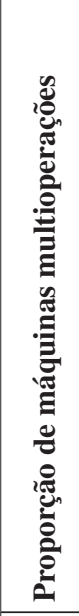 & 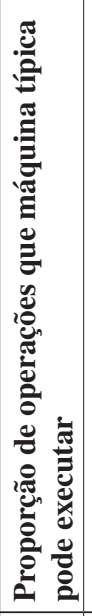 & 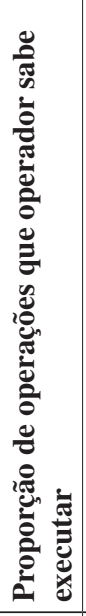 & 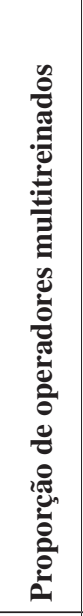 & 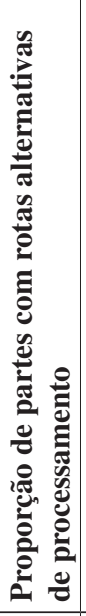 & 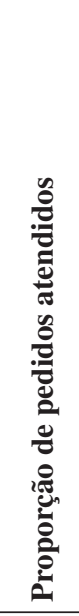 & 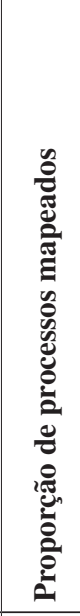 & 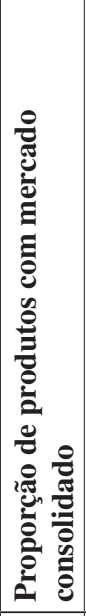 & 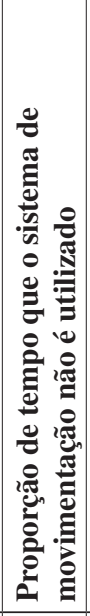 & 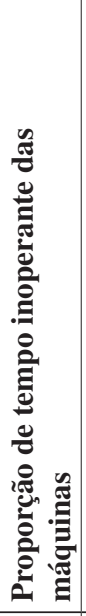 & 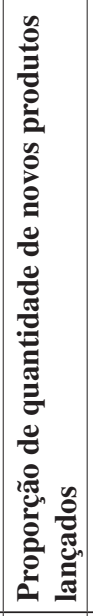 & 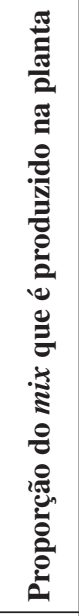 & 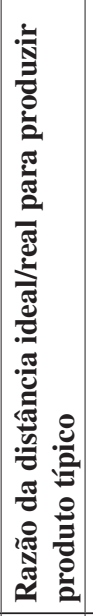 & 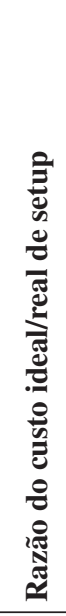 \\
\hline 1 & 1,0 & 3,0 & 3,0 & 3,0 & 3,0 & 3,0 & 1,0 & 3,0 & & & 1,0 & & 1,0 & 5,0 & 3,0 \\
\hline 2 & 3,0 & & 1,0 & 3,0 & 1,0 & 5,0 & 1,0 & 3,0 & & & 3,0 & & 3,0 & 5,0 & \\
\hline 3 & 5,0 & 1,0 & 1,0 & & & 1,0 & 1,0 & 3,0 & & & 3,0 & & 1,0 & 3,0 & 1,0 \\
\hline 4 & & & & 1,0 & 3,0 & & & 1,0 & & & & & & 1,0 & \\
\hline 5 & & & 1,0 & & & & & 5,0 & & & & & & 1,0 & \\
\hline 6 & 5,0 & 1,0 & 3,0 & & & 1,0 & 5,0 & & & & 1,0 & & 5,0 & 5,0 & 3,0 \\
\hline 7 & 1,0 & & & & & & 1,0 & & & & 1,0 & & 1,0 & 1,0 & 1,0 \\
\hline 8 & 3,0 & & 3,0 & & & & 1,0 & & & & 3,0 & & & 1,0 & 1,0 \\
\hline 9 & 3,0 & & & & & & 1,0 & & & & 3,0 & & 1,0 & 1,0 & 1,0 \\
\hline 10 & & & & & & & & & & & 3,0 & & & 5,0 & \\
\hline 11 & & & & & & & & & 1,0 & & 1,0 & & & 1,0 & \\
\hline 12 & & 3,0 & & & & & & & & & & & & 1,0 & \\
\hline 13 & 3,0 & 1,0 & & & & 3,0 & & & & & & 1,0 & & 1,0 & \\
\hline 14 & 3,0 & 3,0 & & & & 1,0 & 5,0 & & & 5,0 & 1,0 & & 3,0 & & \\
\hline 15 & 3,0 & & & & & 1,0 & 3,0 & & & 3,0 & & & 3,0 & 1,0 & \\
\hline 16 & & & & & & & 1,0 & & 3,0 & & & & & & \\
\hline 17 & & 3,0 & & & & 1,0 & & & 1,0 & & & 1,0 & 5,0 & 1,0 & \\
\hline 18 & & 1,0 & & & & & & & 3,0 & & & & 3,0 & & 1,0 \\
\hline 19 & & & & & & & & & 5,0 & & & 1,0 & 1,0 & & \\
\hline 20 & & 3,0 & & & & & & & & & & 3,0 & & 1,0 & \\
\hline 21 & & & & & & & & & 3,0 & & & 5,0 & & & \\
\hline 22 & & & 1,0 & & & & & & 1,0 & & & 3,0 & 1,0 & & \\
\hline 23 & & 3,0 & & & & 3,0 & & & & 1,0 & & & & 1,0 & 1,0 \\
\hline 24 & 1,0 & & & & & 5,0 & & & & 1,0 & & & & & 1,0 \\
\hline 25 & 1,0 & 1,0 & & & & 3,0 & 1,0 & & 1,0 & & & & & & \\
\hline 26 & & & & 5,0 & 5,0 & & 3,0 & & & & & & 1,0 & 1,0 & 1,0 \\
\hline 27 & & & 1,0 & 1,0 & 3,0 & & 1,0 & & & & & & 3,0 & & \\
\hline 28 & & 1,0 & 3,0 & & & 3,0 & 5,0 & & & 5,0 & & & 1,0 & 3,0 & 3,0 \\
\hline 29 & & 3,0 & 3,0 & & 1,0 & 5,0 & & & & 3,0 & 1,0 & & 1,0 & 3,0 & 3,0 \\
\hline 30 & 1,0 & 3,0 & 1,0 & & & & & 3,0 & & 1,0 & & & 1,0 & & 1,0 \\
\hline 31 & 3,0 & & & & & 1,0 & 1,0 & & & & 3,0 & & 1,0 & 3,0 & \\
\hline 32 & 1,0 & 1,0 & & & & 1,0 & & & & & 3,0 & & & 3,0 & \\
\hline 33 & 5,0 & & & & & & & 3,0 & & & 5,0 & & & 3,0 & \\
\hline $\begin{array}{c}\text { Importância } \\
\text { do indicador } \\
\text { Flexibilização } \\
\text { Layout }\left(\mathrm{IIF}_{\mathrm{j}}\right)=\end{array}$ & 0,00 & 0,00 & 0,00 & 0,00 & 0,00 & 0,00 & 0,00 & 0,00 & 0,00 & 0,00 & 0,00 & 0,00 & 0,00 & 0,00 & 0,00 \\
\hline
\end{tabular}


Anexo 1. Continuação...

\begin{tabular}{|c|c|c|c|c|c|c|c|}
\hline 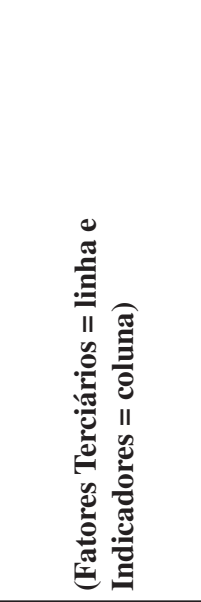 & 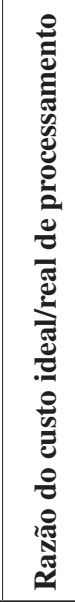 & 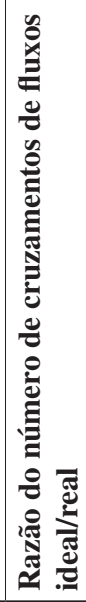 & 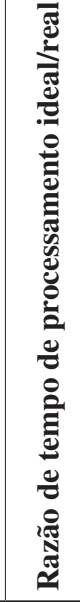 & 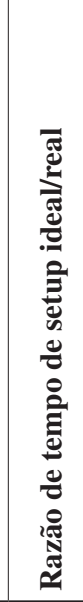 & 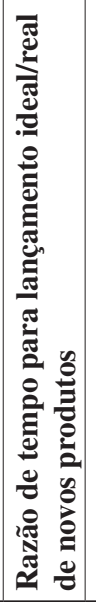 & 画 & 告 \\
\hline 1 & 1,0 & 5,0 & 1,0 & 5,0 & 1,0 & & \\
\hline 2 & 3,0 & 5,0 & 3,0 & & & & \\
\hline 3 & 3,0 & 5,0 & 3,0 & 1,0 & 3,0 & & \\
\hline 4 & 1,0 & 5,0 & & & & & \\
\hline 5 & 1,0 & 3,0 & & & & & \\
\hline 6 & 3,0 & 1,0 & & 3,0 & 1,0 & & \\
\hline 7 & 3,0 & & & 3,0 & & & \\
\hline 8 & 1,0 & & & 1,0 & & & \\
\hline 9 & 1,0 & & & 1,0 & & & \\
\hline 10 & & 1,0 & 3,0 & 1,0 & & & \\
\hline 11 & 3,0 & 3,0 & 3,0 & 1,0 & & & \\
\hline 12 & & & 3,0 & & & & \\
\hline 13 & 3,0 & 3,0 & & 1,0 & & & \\
\hline 14 & & & & & 5,0 & & \\
\hline 15 & & 1,0 & & & & & \\
\hline 16 & & & & & & & \\
\hline 17 & & 1,0 & 5,0 & & 5,0 & & \\
\hline 18 & 1,0 & & 3,0 & & & & \\
\hline 19 & & & & & 5,0 & & \\
\hline 20 & & 1,0 & 3,0 & & 1,0 & & \\
\hline 21 & & & 5,0 & & & & \\
\hline 22 & & & 3,0 & & 3,0 & & \\
\hline 23 & & 1,0 & & & 1,0 & & \\
\hline 24 & & & & & & & \\
\hline 25 & & & & 1,0 & & & \\
\hline 26 & 1,0 & 1,0 & & 1,0 & 1,0 & & \\
\hline 27 & 1,0 & 1,0 & & & 1,0 & & \\
\hline 28 & 1,0 & 3,0 & & 1,0 & 1,0 & & \\
\hline 29 & 1,0 & 3,0 & & & & & \\
\hline 30 & 1,0 & 3,0 & & & 3,0 & & \\
\hline 31 & & 3,0 & & & 1,0 & & \\
\hline 32 & & & & & 1,0 & & \\
\hline 33 & & 1,0 & & & & & \\
\hline $\begin{array}{c}\text { Importância } \\
\text { do indicador } \\
\text { Flexibilização } \\
\text { Layout }\left(\mathrm{IIF}_{\mathrm{j}}\right)=\end{array}$ & 0,00 & 0,00 & 0,00 & 0,00 & 0,00 & & \\
\hline
\end{tabular}

